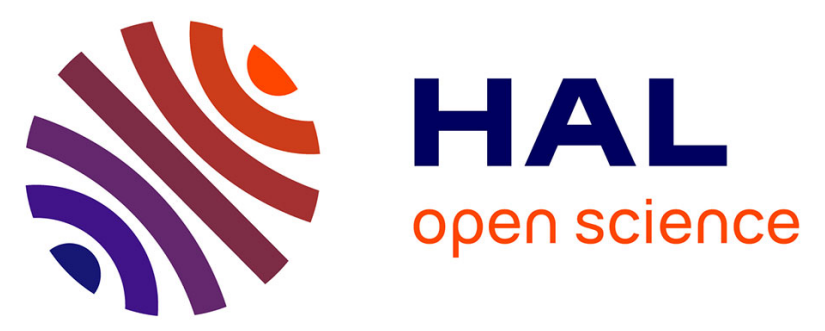

\title{
Adsorption of Benzaldehyde at the Surface of Ice, Studied by Experimental Method and Computer Simulation
}

Melanie Petitjean, György Hantal, Coline Chauvin, Philippe Mirabel, Stephane Le Calve, Paul N.M. Hoang, Sylvain Picaud, Pal Jedlovszky

\section{To cite this version:}

Melanie Petitjean, György Hantal, Coline Chauvin, Philippe Mirabel, Stephane Le Calve, et al.. Adsorption of Benzaldehyde at the Surface of Ice, Studied by Experimental Method and Computer Simulation. Langmuir, 2010, 26 (12), pp.9596-9606. 10.1021/la100169h . hal-02308890

\section{HAL Id: hal-02308890 https://hal.science/hal-02308890}

Submitted on 21 Dec 2020

HAL is a multi-disciplinary open access archive for the deposit and dissemination of scientific research documents, whether they are published or not. The documents may come from teaching and research institutions in France or abroad, or from public or private research centers.
L'archive ouverte pluridisciplinaire HAL, est destinée au dépôt et à la diffusion de documents scientifiques de niveau recherche, publiés ou non, émanant des établissements d'enseignement et de recherche français ou étrangers, des laboratoires publics ou privés. 


\section{Adsorption of Benzaldehyde at the Surface of Ice, Studied by Experimental Method and Computer Simulation}

Mélanie Petitjean, ${ }^{1}$ György Hantal, ${ }^{2,3}$ Coline Chauvin, ${ }^{1}$ Philippe Mirabel, ${ }^{1}$

Stéphane Le Calvé, ${ }^{1 *}$ Paul N. M. Hoang, ${ }^{2}$ Sylvain Picaud, ${ }^{2 *}$ Pál Jedlovszky $3,4^{3 *}$

${ }^{1}$ Laboratoire des Matériaux, Surfaces et Procédés pour la Catalyse (LMSPC, UMR 7515 CNRS/UdS), 25 rue Becquerel, 67087 Strasbourg Cedex 02, France

${ }^{2}$ Institut UTINAM-UMR CNRS 6213, Faculté des Sciences, Université de FrancheComté, F-25030 Besançon Cedex, France

${ }^{3}$ Laboratory of Interfaces and Nanosized Systems, Institute of Chemistry, Eötvös Loránd University, Pázmány Péter stny, 1/a, H-1117 Budapest, Hungary

${ }^{4}$ HAS Research Group of Technical Analytical Chemistry, Szt. Gellért tér 4, H-1111 Budapest, Hungary

Running title: Adsorption of benzaldehyde on ice

*Electronic mail: slecalve@illite.u-strasbg.fr (S.L.C); sylvain.picaud@univ-fcomte.fr (S.P.); pali@chem.elte.hu (P.J.). 


\section{Abstract:}

Adsorption study of benzaldehyde on ice surfaces is performed by combining experimental and theoretical approaches. The experiments are conducted over the temperature range $233-253 \mathrm{~K}$ using a coated wall flow tube coupled to a mass spectrometric detector. Besides the experimental way, the adsorption isotherm is also determined by performing a set of grand canonical Monte Carlo simulations at $233 \mathrm{~K}$. The experimental and calculated adsorption isotherms show a very good agreement within the corresponding errors. Besides, both experimental and theoretical studies permit us to derive the enthalpy of adsorption of benzaldehyde on ice surfaces $\Delta H_{\text {ads, }}$, which are in excellent agreement: $\Delta H_{\mathrm{ads}}=-61.4 \pm 9.7 \mathrm{~kJ} / \mathrm{mol}$ (experimental) and $\Delta H_{\mathrm{ads}}=-59.4 \mathrm{~kJ} / \mathrm{mol}$ (simulation).

The obtained results indicate a much stronger ability of benzaldehyde of being adsorbed at the surface of ice than that of small aliphatic aldehydes, such as formaldehyde or acetaldehyde. At low surface coverages the adsorbed molecules exclusively lie parallel with the ice surface. With increasing surface coverage, however, the increasing competition of the adsorbed molecules for the surface area to be occupied leads to the appearance of two different perpendicular orientations relative to the surface. In the first orientation, the benzaldehyde molecule turns its aldehyde group toward the ice phase, and, similarly to the molecules in the lying orientation, forms a hydrogen bond with a surface water molecule. In the other perpendicular orientation, the aldehyde group turns to the vapor phase, and its $\mathrm{O}$ atom interacts with the delocalized $\pi$ system of the benzene ring of a nearby lying benzaldehyde molecule of the second molecular layer. In accordance with this observed scenario, the saturated adsorption layer, being stable in a roughly $1 \mathrm{~kJ} / \mathrm{mol}$ broad range of chemical potentials, contains, besides the first molecular layer, also traces of the second molecular layer of adsorbed benzaldehyde. 


\section{Introduction}

The upper troposphere is characterized by low temperatures ranging from about 188 to $233 \mathrm{~K}$ and by the presence of ice (cirrus) as well as mixed ice/water clouds covering a substantial portion (up to $25 \%$ ) of the Earth's surface. ${ }^{1}$ Ice clouds are formed in the troposphere at altitudes of $4-15 \mathrm{~km}$, where they can reflect the incoming solar radiation and trap the terrestrial infrared radiation. Depending on the dominant effect, this results either in cooling or warming of the underlying layers of air, according to the particle density, their morphology as well as their (surface) chemical composition. The change of their frequency and distribution, therefore, impacts substantially on the regional and global climate.

The interaction between trace gases and mixed or ice clouds can promote heterogeneous chemistry, and therefore initiate the transfer of chemical species from the gas into the condensed phases. Hydrometeors hence appear to offer a favorable environment for fast physical and chemical transformations that can modify both trace gas and aerosol compositions. ${ }^{2}$ Below approximately $230 \mathrm{~K}$, clouds are predominantly composed of ice crystals with number density ranging from 0.001 to $50 \mathrm{~cm}^{-3}$. 1,3

The presence of oxygenated Volatile Organic Compounds (VOCs), such as alcohols, aldehydes, ketones and carboxylic acids in the upper troposphere is also well established, ${ }^{4-7}$ and could be explained as a consequence of a rapid convection from the polluted boundary layer. ${ }^{8}$ The photolysis of carbonyl compounds, such as aldehydes and ketones is a net source of $\mathrm{OH}$ and $\mathrm{HO}_{2}$ radicals, and hence leads to an enhanced abundance of these oxidants as well as of peroxyacetyl nitrate. Enhanced production of main oxidants of the atmosphere can then affect the concentrations of many other trace gases, and is likely to modify the ozone cycling reactions in this region.

Many recent experimental and theoretical studies have been focused on the adsorption of oxygenated VOCs (alcohols, acetic acid, acetone, etc.) on pure ice surfaces. ${ }^{9-18}$ The experimental results have highlighted that even if the interaction between the organic compounds and pure ice is strong enough to lead to a monolayer adsorption in laboratory experiments, ${ }^{10-14,19}$ the occurrence of cirrus clouds in the upper troposphere region will not affect significantly the gas phase concentrations of oxygenated organic compounds. Experimental investigations can be well complemented by computer simulations, which 
provide an atomistic level insight into the three-dimensional structure of the adsorption layer. On the other hand, results of computer simulation studies can only be verified by comparing them to experimental data. Among the various computer simulation techniques the grand canonical Monte Carlo (GCMC) method $^{20,21}$ is of particular importance in addressing this problem, since in such simulations a real adsorption experiment can be modeled by systematically varying the chemical potential of the VOC and determining its surface concentration as a function of the chemical potential. The GCMC method has successfully been applied to a set of different adsorption processes, such as the adsorption of VOCs on ice, ${ }^{15-18}$ as well as of water at the surface of various carbonaceous materials, ${ }^{22-27}$ covalent organic frameworks, ${ }^{28}$ silica, ${ }^{29,30}$ self-assembled monolayers, ${ }^{31}$ and several metal oxides. ${ }^{32-35}$

In spite of the increasing interest of the problem of VOC adsorption at the ice surface due to its great atmospheric relevance, to the best of our knowledge, no study has been focused so far on the adsorption of aromatic oxygenated VOCs on ice surfaces, although the presence of a phenyl group can likely modify the behavior of the adsorbed molecule. Benzaldehyde represents the dominant species of aromatic carbonyl compounds in the troposphere. ${ }^{36}$ In addition, benzaldehyde can be considered as a simple model of aromatic aldehydes. It can be found in fruits, and is used as a soil fumigant and in the manufacturing of deodorants/air fresheners and loose mineral wool fiber. ${ }^{16}$ Benzaldehyde is also produced in situ in the atmosphere by oxidation of various VOCs, such as toluene. ${ }^{36}$

The goal of the present study is to examine the interaction of benzaldehyde with ice surfaces at temperatures relevant for the upper troposphere. Our approach of investigation combines experiments (adsorption measurement) and theory (computer simulation), as in this way we can get more detailed and relevant information on the system studied than what could be reached either by experiment or theory alone. Surface coverages of benzaldehyde on ice have been experimentally measured for temperatures ranging from $233 \mathrm{~K}$ to $253 \mathrm{~K}$. Our experimental data were then compared with those obtained in this work by GCMC simulations performed at $233 \mathrm{~K}$ on a model proton-disordered ice surface. To our knowledge, this work is the first to report uptake of benzaldehyde on ice surfaces for temperatures relevant of the mid and upper troposphere. This paper reports also the first joint experimental and theoretical adsorption study of an aromatic species on ice. 


\section{Methods}

2.1. Adsorption Experiments. The uptake of benzaldehyde on ice surfaces was studied using a vertical coated wall flow tube coupled to a mass spectrometer, already described elsewhere. ${ }^{10,11,37,38}$ We will therefore provide only a brief summary of its principle operation. The apparatus has a double jacket to allow the system to be operated at low temperature. The cooling fluid was circulated in the inner jacket from a cooler/circulator (Huber, Unistat 385) while vacuum was maintained in the outer jacket for thermal insulation. The temperature of the flow tube could be cooled down and regulated between 188 and $253 \mathrm{~K}$. The jacketed flow tube was approximately $40 \mathrm{~cm}$ in length with an internal diameter of $2.8 \mathrm{~cm}$. The ice surface was prepared by totally wetting, with Milli-Q water $(18 \mathrm{M} \Omega \mathrm{cm})$, the inner wall of the flow tube that was precooled to $263 \mathrm{~K}$. The viscous aqueous film was then cooled down to $253 \mathrm{~K}$ to obtain a solid film that can be retained during the course of the experiments. Finally, the film was cooled directly to the desired temperature over a period of 10-15 min. The thickness of the ice film was estimated between 48 and $60 \mu \mathrm{m}$ by weighting the resulting liquid water, when the ice film was melted at the end of the experiment.

The helium carrier gas (UHP certified to $>99.9995 \%$ from Messer) was used without further purification. During the experiment, water vapor was added to the main helium flow in order to provide a partial pressure of water, equal to the vapor pressure of water over the ice film and therefore inhibit net evaporation of this film. The resulting humidified helium flow was injected at the upstream end of the flow reactor.

Benzaldehyde ( $\geq 98 \%$ ) purchased from Acros Organics was further purified before being used by repeated freeze, pump, and thaw cycles. To perform an experiment, benzaldehyde was premixed with helium in a 101 glass light-tight bulb to form $5.68 \times 10^{-2}-0.116 \%$ mixtures, at a total pressure of $\sim 0.99 \times 10^{5}-1.03 \times 10^{5} \mathrm{~Pa}$. The mixture containing benzaldehyde was injected into the flow tube reactor via a sliding injector that allows changing the exposed ice surfaces $\left(140-270 \mathrm{~cm}^{2}\right)$. The injector was jacketed, and a heating tape was wound up in the jacket, to ensure a gentle heating. ${ }^{11}$

All the gases flowed into the reactor through Teflon tubing. The gas mixture containing benzaldehyde and water vapor diluted in helium was flowed through the reactor with a linear velocity ranging between 30 and $100 \mathrm{~cm} / \mathrm{s}$. Concentrations of benzaldehyde in 
the gas phase were calculated from their mass flow rates, temperature and pressure in the flow tube. All the flow rates were controlled and measured with calibrated mass flowmeters (Millipore, 2900 series). The pressure that ranged between 250 and $330 \mathrm{~Pa}$ was measured with two capacitance manometers (Edwards, 622 Barocel, range 0-13000 Pa, and Keller, PAA-41, range 0-10000 $\mathrm{Pa}$ ) connected at the top and bottom of the flow tube. Under our experimental conditions, the mixing time $\tau_{\text {mix }}$ between benzaldehyde flow and the main He flow was lower than $2 \mathrm{~ms},{ }^{19}$ which corresponds to a mixing length smaller than $0.3 \mathrm{~cm}$.

The gas stream coming out of the flow tube was analyzed using a differentially pumped mass quadruple spectrometer Pfeiffer Vacuum QMS. Benzaldehyde was monitored at the main fragment ion $\mathrm{CH}_{3} \mathrm{CO}^{+}$peak at $m / z=43$ amu using a temporal resolution of $30 \mathrm{~ms}$, an ionization energy of $60 \mathrm{eV}$ and an emission current of $1000 \mu \mathrm{A}$.

2.2. Computer Simulations. In modeling the adsorption of benzaldehyde on ice, a series of 29 Monte Carlo simulations has been performed on the grand canonical $(\mu, V, T)$ ensemble at the temperature $T=233 \mathrm{~K}$. The $X, Y$ and $Z$ edges of the basic simulation box have been $100 \AA$, $35.926 \AA$, and $38.891 \AA$ long, respectively, $X$ being the axis perpendicular to the ice surface. Standard periodic boundary conditions have been applied. In modeling the ice phase 18 molecular layers of water, containing 160 molecules each, have been placed in the middle of the basic simulation box in the arrangement corresponding to the geometry of proton-disordered $\mathrm{I}_{\mathrm{h}}$ ice. The chemical potential of benzaldehyde $\mu$ has been systematically varied in the simulations from -70.31 to $-60.66 \mathrm{~kJ} / \mathrm{mol}$. In this way, the adsorption isotherm has simply been obtained as the average number of the benzaldehyde molecules in the system $\langle N\rangle$ as a function of their chemical potential. The benzaldehyde chemical potential values corresponding to the different simulations as well as the resulting values of $\langle N\rangle$ are collected in Table 1.

Water molecules have been described by the rigid five site TIP5P potential, ${ }^{40}$ since the melting point of this model is known to be rather close to that of real water. ${ }^{41}$ Benzaldehyde has been modeled by the OPLS force field ${ }^{42}$ using the charge distribution calculated by Canneaux et $a l{ }^{43}$ The interaction energy of two molecules has been calculated as the sum of their site-site Lennard-Jones and charge-charge Coulomb interactions. All interactions have been truncated to zero beyond the molecular centre-centre cut-off distance of $12.5 \AA$. The total potential energy of the system has been calculated as the sum of the pair interaction energies of all molecule pairs. 
In the simulations, performed by using the program $\mathrm{MMC}^{44}$ particle displacement and benzaldehyde insertion/deletion attempts have been done in alternating order. In a particle displacement step a randomly chosen molecule has been randomly displaced by no more than $0.25 \AA$ and randomly rotated around a randomly chosen space-fixed axis by no more than $15^{\circ}$. Water and benzaldehyde molecules have been selected for such moves with equal probabilities. Particle insertion/deletion steps have been done using the cavity biased algorithm of Mezei. ${ }^{45,46}$ Thus, new molecules have only been tried to be inserted into empty cavities of the minimum radius of $2.9 \AA$. Suitable cavities have been searched for in the system along a $100 \times 100 \times 100$ grid, which has been regenerated after every million Monte Carlo steps. Particle insertion and deletion attempts have been done in alternating order.

The systems have been equilibrated by performing 100 - 500 million Monte Carlo steps. The number of benzaldehyde molecules in the system has then been averaged over $300-400$ million equilibrium configurations. Finally, at selected chemical potential values 2000 sample configurations, separated from each other by 100000 Monte Carlo steps each, have been saved for detailed analyses. In these analyses the two ice surfaces present in the basic box have been treated separately, thus, all the results have been averaged not only over the 2000 sample configurations, but also over these two ice surfaces per system.

\section{Adsorption Isotherm}

3.1. Experimental Isotherms. Uptake experiments were performed by first establishing a highly stable flow of benzaldehyde in the injector, this injector being positioned past the end of the ice film. The injector was then moved quickly to an upstream position so that the ice film was exposed to benzaldehyde. The uptake of benzaldehyde on the ice film leads to a drop of signal as shown in Figure 1. After a time-scale ranging from several seconds to a few minutes depending on the concentration of the gas mixture, the ice surface was then saturated, and the MS-signal returned to its initial level. When the injector was pushed back, benzaldehyde desorbed from the ice surface and the signal increased and then again returned to its initial level. Similar experiments were conducted over the temperature range of $233-253 \mathrm{~K}$ and for gas phase concentrations varying from $1.56 \times 10^{12}$ to $1.87 \times 10^{13}$ molecules $/ \mathrm{cm}^{3}$. 
3.1.1. Surface Coverage. The number of benzaldehyde molecules adsorbed on the ice surface $N_{\text {ads }}$ was determined from the integrated area of the adsorption peak and the total flow rate in the flow tube. The surface coverage $N$ of benzaldehyde was then calculated from the geometric exposed ice surface area $A_{\text {ice }}$ as to $N=N_{\text {ads }} / A_{\text {ice. }}$ The experiments were performed several times, using newly generated ice surfaces and several gas mixtures in order to ensure the reproducibility of the data.

Surface coverage $N$ versus gas phase concentrations is plotted in Figure 2 for three temperatures, i.e., 233, 243 and $253 \mathrm{~K}$. The relative errors on the gas phase concentrations, which range between 8 and $16 \%$ (horizontal error bars in this figure) have been calculated from the possible uncertainties of the total pressure in each flow. The quoted errors on $N$ (vertical error bars) arise from uncertainties made on the total flow rate, exposed ice area and concentrations in the gas phase. They also include a systematic $2 \%$ error that corresponds to the error on the integrated area of adsorption peaks. These resulting errors on $N$ vary between 15 and $27 \%$.

3.1.2. Langmuir Fit of the Isotherms and Heat of Adsorption. Since the main assumptions of the Langmuir theory, namely that (i) adsorption cannot proceed beyond monolayer coverage, and (ii) the adsorption of a new particle occurs independently from the occupancy of other adsorption sites, are certainly valid in the pressure range of our measurements, we used this theory to analyze our experimental data. According to this theory, the number of molecules adsorbed per unit area of ice surface is related to the concentration of benzaldehyde in the gas phase as

$$
\theta=\frac{N}{N_{\mathrm{M}}}=\frac{K_{\mathrm{ads}}(T)[\text { benzaldehy de }]_{\mathrm{gas}}}{1+K_{\mathrm{ads}}(T)[\text { benzaldehy de }]_{\mathrm{gas}}},
$$

where $\theta$ is the fractional coverage, $N_{\mathrm{M}}$ is the monolayer capacity, the brackets $[\ldots]_{\text {gas }}$ stand for the gas phase concentration, and $K_{\mathrm{ads}}(T)$ is the temperature dependent adsorption constant that describes partitioning between adsorbed and non-adsorbed molecules. 
From a thermodynamic point of view, the equilibrium between the gas phase and the surface can also be expressed by using a dimensionless, temperature dependent partition coefficient, $K(T)$ :

$$
\frac{N}{[\text { benzaldehy de }]_{\text {gas }}} \times \frac{A}{V}=\exp \left(\frac{\Delta G_{\mathrm{ads}}}{R T}\right)=K(T),
$$

where $R$ is the gas constant, $A / V$ is the area-to-volume ratio of an ideal gas adsorbed at the surface, and $\Delta G_{\text {ads }}$ is the free energy of adsorption. $A / V$ defines the standard state for the adsorbed phase. In absence of general agreement on the choice of a standard state, the ratio of $A / V$ is conveniently considered equal to $\sim 1.7 \times 10^{7} \mathrm{~cm}^{-1},{ }^{47,48}$ which corresponds to the molar area of $3.74 \times 10^{7} \mathrm{~m}^{2} / \mathrm{mol}$. Note that the enthalpy does not depend on the choice of standard states. ${ }^{49}$ The advantage of the chosen standard state is its independence of temperature, particle size, and absolute values of both $V$ and $A .{ }^{50} \Delta G_{\text {ads }}$ is related to the enthalpy and entropy of adsorption ( $\Delta H_{\text {ads }}$ and $\Delta S_{\text {ads }}$, respectively) via the Gibbs equation:

$$
\Delta G_{\mathrm{ads}}=\Delta H_{\mathrm{ads}}-T \Delta S_{\mathrm{ads}}=-R T \ln K(T)
$$

At low concentrations $K_{\text {ads }}(T)$ [benzaldehyde $]_{\text {gas }}<<1$, therefore, using eqs. 1 and 2 , the relation of $K$ and $K_{\text {ads }}$ can be written as follows:

$$
K_{\mathrm{ads}}(T) \times N_{\mathrm{M}}=K(T) \times \frac{V}{A} .
$$

In addition, $N$ increases linearly with the concentration of benzaldehyde with a slope of $N_{\mathrm{M}} \times K_{\text {ads }}(T)$ or $K(T) \times V / A$ :

$$
N=K_{\mathrm{ads}}(T) \times N_{\mathrm{M}} \times[\text { benzaldehy de }]_{\text {gas }}=K(T) \times \frac{V}{A} \times[\text { benzaldehy de }]_{\mathrm{gas}} .
$$


Figure 2 shows linear isotherms on pure ice of $N$ versus [benzaldehyde] gas at 233, 243 and $253 \mathrm{~K}$. The resulting values of both $K(T)$ and $K_{\text {ads }} \times N_{\mathrm{M}}$ are derived from the slope of these plots according to eq. 5 and are reported in Table 2. For each temperature, $\Delta G_{\text {ads }}$ can be obtained from the value of $K$ according to eq. 3 .

The temperature dependence of $K(T)$ between 233 and $253 \mathrm{~K}$ can, in principle, be used to determine the adsorption enthalpy $\Delta H_{\text {ads }}$ of benzaldehyde on pure ice according to eq. 3 . The plot of $\ln K$ versus $1 / T$ is linear for the temperature range $233-253 \mathrm{~K}$ (see Figure 3 ). However, the linear fit of $\ln K$ versus $1 / T$ leads to large uncertainties since we only have three points to be fitted. Indeed, the adsorption enthalpy value resulted from a linear weighted least-squares fitting of these data is $\Delta H_{\text {ads }}=-46 \pm 8 \mathrm{~kJ} / \mathrm{mol}$ (the quoted error is given at $2 \sigma$ level $+5 \%$ ). Further, this value of $\Delta H_{\mathrm{ads}}$ is slightly higher than the enthalpy of condensation of $-50.3 \mathrm{~kJ} / \mathrm{mol},{ }^{51}$ which is thermodynamically not consistent. Therefore, we used a different approach to determine the adsorption enthalpy of benzaldehyde on ice at the temperatures of the measurements. Thus, $\Delta S_{\text {ads }}$ was fixed according to the Trouton's rule, ${ }^{52}$ where $\Delta S_{\mathrm{ads}} \sim \Delta S_{\mathrm{vap}}=\Delta H_{\mathrm{vap}} / T_{\mathrm{b}}, T_{\mathrm{b}}$ being the boiling temperature. According to this last equation, $\Delta S_{\mathrm{ads}}$ is then $-111.3 \mathrm{~J} / \mathrm{K}$ mol for benzaldehyde. Substituting the obtained value to eq. $3 \Delta H_{\text {ads }}$ can be then calculated. As shown in Table 2, the resulting values for $\Delta H_{\text {ads }}$ are the following (in units of $\mathrm{kJ} / \mathrm{mol}$ ): $-61.4 \pm 9.7$ (233 K), $-61.85 \pm 9.9$ $(243 \mathrm{~K})$, and $-62.7 \pm 10.0(253 \mathrm{~K})$, where the quoted errors correspond to $2 \sigma$ levels $+5 \%$.

3.1.3. Comparison with Previous Studies. Since this study is the first to report adsorption of benzaldehyde on ice surfaces, the comparison is rather limited. Nevertheless, our experimental data can be conveniently compared with those obtained in a previous work for acetaldehyde. ${ }^{9}$ As shown in Figure 4, for a given gas phase concentration, the number of benzaldehyde molecules adsorbed on ice is much higher than that obtained for acetaldehyde at $233 \mathrm{~K}$. The same behavior has been observed for the two other studied temperatures, i.e. 243 and $253 \mathrm{~K}$. The ratio between the two slopes is 1.7 at $253 \mathrm{~K}$ and reaches up to 12.1 at $233 \mathrm{~K}$.

3.2. Isotherm Resulted from Computer Simulations. The calculated adsorption isotherm is shown in Figure 5 in the $\langle N\rangle$ vs. $\mu$ form. As is seen, at low chemical potentials it shows an exponential increase up to the $\mu$ value of about $-62 \mathrm{~kJ} / \mathrm{mol}$. The exponential increase of the isotherm indicates that the adsorption of an individual molecule at the ice surface is 
independent from the presence or absence of other adsorbed benzaldehyde molecules. Then, in the chemical potential range between -62.0 and $-61.1 \mathrm{~kJ} / \mathrm{mol}$ the isotherm exhibits a saturation plateau, where the surface density of the benzaldehyde molecules is about $6.7 \mu \mathrm{mol} / \mathrm{m}^{2}$. This plateau corresponds to the presence of a particularly stable adsorption layer. It should be noted that such a saturation plateau was found to be completely missing from the adsorption isotherm of formaldehyde on ice. ${ }^{16}$ Properties of this stable layer are analyzed in detail in a following section. Finally, between the $\mu$ values of -61.1 and $-61.05 \mathrm{~kJ} / \mathrm{mol}$ condensation of benzaldehyde occurs; above this chemical potential the system contains liquid benzaldehyde.

Considering the behavior of the calculated isotherm we have chosen three different chemical potential values at which detailed analysis of the adsorption layer is performed. Thus, system I, corresponding to the chemical potential value of $-63.75 \mathrm{~kJ} / \mathrm{mol}$ is located at the exponentially rising part of the isotherm. At this chemical potential value even the first molecular layer of the adsorbed benzaldehyde molecules is far from being saturated. System II, being at the $\mu$ value of $-62.21 \mathrm{~kJ} / \mathrm{mol}$ is located close to the saturation plateau, whereas system III is chosen to be at this plateau, at $\mu=-61.44 \mathrm{~kJ} / \mathrm{mol}$, where the benzaldehyde molecules form their particularly stable adsorption layer. Instantaneous equilibrium snapshots of systems I-III are shown in Figure 6 as taken out from the simulations.

3.3. Comparison of the Experimental and Simulated Isotherms. The experimental and calculated isotherms can be compared by plotting the surface density of the adsorbed molecules $\Gamma$ versus the relative vapor pressure of benzaldehyde $p_{\text {rel }}$ (i.e., its pressure $p$ normalized by the pressure of its saturated vapor $p_{0}$ ). Although the experimental saturated vapor pressure $p_{0}$ of benzaldehyde at $233 \mathrm{~K}$ is not available in the literature, it can be extrapolated from vapor pressure measurements performed at other temperatures using the Antoine equation:

$$
\ln p_{0}=A-\frac{B}{T+C}
$$

Using the Antoine parameter values ${ }^{53}$ of $A=16.35, B=3748.62 \mathrm{~K}$, and $C=-66.12 \mathrm{~K}$, corresponding to the pressure value in Torr units, the $p_{0}$ value of $0.295 \mathrm{~Pa}$ can be derived at $233 \mathrm{~K}$. 
The simulated isotherm can be converted to the $\Gamma$ vs. $p_{\text {rel }}$ form using the relation ${ }^{32}$

$$
p_{\text {rel }}=\frac{p}{p_{0}}=\frac{\exp (\beta \mu)}{\exp \left(\beta \mu_{0}\right)}
$$

where $\beta=1 / k_{\mathrm{B}} T, k_{\mathrm{B}}$ being the Boltzmann constant, and $\mu_{0}$ is the chemical potential value corresponding to the point of condensation. From the calculated isotherm the value of $\mu_{0}$ has been determined to be $-61.075 \mathrm{~kJ} / \mathrm{mol}$. The $\Gamma$ and $p_{\text {rel }}$ values corresponding to the different systems simulated are also included in Table 1.

The comparison of the experimental and calculated isotherms obtained at $233 \mathrm{~K}$ is presented in Figure 7. As is seen, the two isotherms are in excellent agreement with each other, although the simulation data correspond to slightly lower surface coverage values, the two set of data agrees with each other almost within the error bars. The observed agreement of the simulated and experimental isotherms confirms the validity of the computer model used, and demonstrates the relevance of the detailed analysis of the simulated configurations.

It should finally be noted that the simulated isotherm, determined in the entire $0 \leq p_{\text {rel }} \leq 1$ pressure range clearly shows a non-Langmuir behavior above the pressure range explored in the experiments. This non-Langmuir behavior, already suggested by the presence of the saturation plateau of the isotherm in the $\langle N\rangle$ vs $\mu$ form (see Fig. 5), is in a clear contrast with our previous finding concerning the adsorption of formaldehyde on ice, ${ }^{16}$ and it is very probably due to the non-negligible lateral interaction of the adsorbed benzaldehyde molecules at moderate and high surface coverages.

\section{Characterization of the Adsorption Layer}

4.1. Density Profiles. The density profile of the benzaldehyde molecules in systems I-III is shown in Figure 8. In calculating these profiles the position of the benzene ring $\mathrm{C}$ atom to which the CHO group is attached has represented the position of the entire benzaldehyde molecule. As is seen, in system I the obtained profile is unimodal, having its peak at the $X$ value

of $33.9 \AA$, just about $2 \AA$ away from the point where the ice density drops to zero. This close contact with the ice phase suggests that the benzaldehyde molecules in this system are probably 
lying parallel with the ice surface. However, in system II the density peak of the benzaldehyde molecules is already bimodal. The first maximum of the broad, split peak is close to the position of the peak in system I, whereas the second maximum appears farther away from the ice phase, i.e., at $X=35.1 \AA$. The fact that the density peak is now split into two separate maxima indicates that the adsorbed molecules are aligned in two different orientations relative to the ice surface. Further, the fact that the second maximum is almost $1 \AA$ farther away from the ice phase than the first one suggests that, besides the parallel-like orientation corresponding to the first maximum, the other preferred alignment of the benzaldehyde molecules is probably close to be perpendicular to the surface. This point is investigated in detail in the following sub-section.

Finally, in system III the benzaldehyde density profile exhibits again a unimodal peak, now at $X=35.4 \AA$, close to the position of the second maximum of the split peak of system II, and only a shoulder is seen around the $X$ value of $34 \AA$. This main peak is followed by a small second peak around the $X$ value of $37.7 \AA$. This finding suggests that (i) in system III, i.e., when benzaldehyde forms a particularly stable adsorption layer at the ice surface, the dominant orientation of its molecules is already more or less perpendicular to the surface (in accordance with the simple expectation that the number of adsorbed molecules being in contact with the ice surface can be maximized this way), and (ii) besides the already saturated first molecular layer, traces of a second molecular layer are also present in this stable adsorption layer of the benzaldehyde molecules.

4.2. Orientation of the Adsorbed Molecules. In describing the orientational statistics of rigid molecules relative to an external surface the bivariate joint distribution of two independent orientational variables has to be calculated. ${ }^{54,55}$ We have shown that the angular polar coordinates $\vartheta$ and $\phi$ of the surface normal vector in a local Cartesian frame fixed to the individual molecules are a sufficient choice of such variables. ${ }^{54,55}$ However, since the polar angle $\vartheta$ is formed by two general spatial vectors, but $\phi$ is the angle of two vectors restricted to lie in a given plane (i.e., the $x y$ plane of the local frame) by definition, uncorrelated orientation of the molecules with the surface results in a uniform bivariate distribution only if $\cos \vartheta$ and $\phi$ are chosen to be the independent variables.

In analyzing the orientation of the adsorbed benzaldehyde molecules relative to the ice surface we defined this local Cartesian frame in the following way. The origin of this frame is 
the $\mathrm{O}$ atom, its $z$ axis points along the $\mathrm{O}=\mathrm{C}$ double bond, axis $y$ also lies in the plane of the molecule in such a way that the $y$ coordinate of the $\mathrm{H}$ atom of the $\mathrm{CHO}$ group is negative, and axis $x$ is perpendicular to the molecular plane. Finally, we use the convention that the surface normal vector $\underline{X}$ is directed from the bulk ice phase towards the adsorption layer. It should also be noted that, due to the planar symmetry of the benzaldehyde molecule, this frame is always chosen in such a way that $\phi$ does not exceed $180^{\circ}$. The definition of this local Cartesian frame and of the polar angles $\vartheta$ and $\phi$ of the surface normal vector pointing away from the ice phase $\underline{X}$ in this frame is illustrated in Figure 9.

The $P(\cos \vartheta, \phi)$ orientational maps of the adsorbed benzaldehyde molecules in systems IIII are shown in Figure 10. As is seen, at low surface coverages (i.e., in system I) the $P(\cos \vartheta, \phi)$ distribution exhibits two sharp peaks at about $\cos \vartheta=0.1$ and $\phi=0^{\circ}$, and at $\cos \vartheta \sim 0.1$ and $\phi=180^{\circ}$. These peaks correspond to the same preferred alignment, denoted here by $\alpha$, i.e., when the benzaldehyde molecule lies almost parallel with the ice surface, and the $\mathrm{C}=\mathrm{O}$ bond declines slightly, by about $5-10^{\circ}$ from the surface plane pointing towards the ice phase with the $\mathrm{O}$ atom. With increasing surface coverage also another peak of the $P(\cos \vartheta, \phi)$ map, marked here by $\beta$, emerges around its $\cos \vartheta \sim 0.2, \phi=90^{\circ}$ point. Thus, in system II this peak is only seen as a small secondary maximum, but in system III it becomes the dominant feature of the orientational map. In this alignment the plane of the benzaldehyde molecule is perpendicular to the ice surface, the $\mathrm{C}=\mathrm{O}$ double bond declines from the parallel alignment with the surface by about $15-20^{\circ}$, the benzene ring points to the vapor, whereas the $\mathrm{C}-\mathrm{H}$ bond of the aldehyde group rather straight to the ice surface. Finally, in system III, i.e., in the stable adsorption layer of benzaldehyde a third orientation, corresponding to the $\cos \vartheta$ value of -1 is also slightly preferred. In this orientation, denoted by $\gamma$ the benzaldehyde molecule is again perpendicular to the ice surface, but now points by its $\mathrm{C}=\mathrm{O}$ group straight away from the ice phase. The preferred orientations $\alpha, \beta$ and $\gamma$ of the adsorbed benzaldehyde molecules are illustrated in Fig. 10.

The preference of the adsorbed molecules for an almost parallel alignment with the surface at low coverages, and the increasing importance of the nearly perpendicular alignments with increasing surface coverage are in accordance with our previous assumptions, made in the density profile analysis. In order to demonstrate the relation between these orientational preferences with the shape of the density peaks in the systems of relatively high surface 
coverages we have calculated in systems II and III the density profiles of the molecules of different orientations separately. This deconvolution of the density peaks according to the molecular orientations is shown in the insets of Fig. 8. This analysis reveals that the first maximum of the split density peak in system II and the shoulder at the ice phase side of the main peak in system III, similarly to the entire peak in system I, are indeed given by the benzaldehyde molecules of orientation $\alpha$, i.e., the ones that lie almost parallel with the ice surface. Further, the second maximum of the split density peak of system II as well as the main peak of system III are given by the molecules that are perpendicular to the surface. Benzaldehyde molecules of orientation $\gamma$ in system III contribute to the high $X$ side of the main density peak, leading to a broadening of this peak with respect to that in system II farther away from the ice surface. Finally, it is also seen that the molecules forming traces of the second molecular layer in system III (i.e., the ones contributing to the small second density peak in this system) are again in orientation $\alpha$, lying parallel with the ice surface.

In understanding the origin of these preferences of the adsorbed molecules their possible interactions with the rest of the system at different surface coverages have to be considered. Thus, in the case of highly unsaturated outmost molecular layers, such as the first molecular layer in system I and the second molecular layer in system III the interaction of the molecules of this layer with the rest of the system can be maximized in their lying orientation $\alpha$, when all of their atoms can get as close to the ice phase or to the inner layer as possible. Further, in this alignment the delocalized $\pi$ electron system of the benzene ring can interact with the nearby $\mathrm{O}$ atoms of high electronegativity (i.e., with the water $\mathrm{O}$ atoms at the ice surface in the case of system I, and with the outward oriented $\mathrm{O}$ atoms of the benzaldehyde molecules of alignment $\gamma$ in the first molecular layer in the case of system III). Finally, the slight, 5-10 deviation of the $\alpha$ oriented molecules from the exactly parallel alignment with the surface in system I allows them to form hydrogen bonds with the flatly aligned surface $\mathrm{O}-\mathrm{H}$ groups ${ }^{15}$ of the ice phase, as illustrated in Figure 11a.

Upon saturation of the first molecular layer, however, the increasing amount of the adsorbed benzaldehyde molecules increasingly compete for the area to be occupied at the surface, and this competition gives rise to their preference for the perpendicular orientation. Among these alignments orientation $\beta$ is stabilized by a hydrogen bond formed with a surface water molecule (see Fig. 11.b). Finally, the preference of the benzaldehyde molecules for 
orientation $\gamma$ occurs simultaneously with the appearance of the second molecular layer in system III, since $\gamma$ oriented molecules of the first molecular layer can stabilize the $\alpha$ oriented, lying molecules of the second molecular layer through the interaction of the outward oriented $\mathrm{O}$ atom of the former, and the lying aromatic benzene ring of the latter molecule (see Fig. 11.c).

4.3. Energetics of the Adsorption. In order to analyze also the energetic background of the adsorption we have calculated the distribution of the $U_{\mathrm{b}}$ binding energy of an adsorbed benzaldehyde molecule (i.e., its interaction energy with the rest of the system) as well as that of its contributions coming from the interaction with the ice phase, $U_{\mathrm{b}}^{\text {ice }}$, and with the other adsorbed benzaldehyde molecules, $U_{\mathrm{b}}^{\mathrm{BA}}$. The distribution of the $U_{\mathrm{b}}$ binding energy and its contributions $U_{\mathrm{b}}^{\text {ice }}$ and $U_{\mathrm{b}}^{\mathrm{BA}}$ are shown in Figure 12 as obtained in systems I-III.

In system I the distribution of the ice contribution to the total binding energy $\mathrm{P}\left(U_{\mathrm{b}}^{\text {ice }}\right)$ is unimodal, having its peak at about $-64 \mathrm{~kJ} / \mathrm{mol}$. The unimodality of this peak is in accordance with our previous finding that here all the adsorbed molecules are aligned in a rather similar way. The mean value of this distribution turns out to be $-59.4 \mathrm{~kJ} / \mathrm{mol}$, which agrees roughly with the sum of ice-substrate interaction energies obtained for benzene $(-39 \mathrm{~kJ} / \mathrm{mol}$, measured at the surface of amorphous solid water at $141 \mathrm{~K})^{56}$ and for formaldehyde $(-27.3 \mathrm{~kJ} / \mathrm{mol}$, obtained from computer simulation at the surface of $I_{h}$ ice at $\left.200 \mathrm{~K}\right)^{16}$ at low surface coverages. Further, this value is in an excellent agreement with the experimental value of the adsorption enthalpy of $-61.2 \pm 10.2 \mathrm{~kJ} / \mathrm{mol}$, obtained at very low surface coverages (i.e., when benzaldehydebenzaldehyde interactions are negligible), as derived from eq. 3.

In system II the $\mathrm{P}\left(U_{\mathrm{b}}^{\text {ice }}\right)$ distribution is bimodal: besides its peak around $-58 \mathrm{~kJ} / \mathrm{mol}$ it also exhibits another, higher peak at about $-38 \mathrm{~kJ} / \mathrm{mol}$. This bimodal shape of the $\mathrm{P}\left(U_{\mathrm{b}}^{\text {ice }}\right)$ distribution is consistent with the dual orientational preferences of the adsorbed molecules in this system. Clearly, the peak at lower energies is given by the $\alpha$, whilst that at higher energies by the $\beta$ oriented benzaldehyde molecules (see the upper inset of Fig. 12). Considering the fact that the benzaldehyde molecule can form one hydrogen bond with the surface water molecules in both of these orientations, the roughly $20 \mathrm{~kJ} / \mathrm{mol}$ difference between the positions of these peaks 
provides an estimate for the strength of the electron transfer interaction from the aromatic benzene ring toward the highly electronegative water $\mathrm{O}$ atom, which occurs only in orientation $\alpha$.

Finally, in system III the $\mathrm{P}\left(U_{\mathrm{b}}^{\text {ice }}\right)$ distribution exhibits only a shoulder at $-58 \mathrm{~kJ} / \mathrm{mol}$, its main peak appears at about - $34 \mathrm{~kJ} / \mathrm{mol}$, this peak exhibits another shoulder at its high energy side around $-14 \mathrm{~kJ} / \mathrm{mol}$, and the distribution has another small peak close to zero. As is expected, the shoulder at low energies are given by the few $\alpha$ oriented molecules, similarly to system II the main peak is again due to the molecules of orientation $\beta$, the high energy side shoulder of this peak can be attributed to the molecules of orientation $\gamma$, which cannot form hydrogen bond with the ice surface, whereas the peak around zero energies is given by the $\alpha$ oriented molecules of the second molecular layer, already not being in contact with the ice phase (see the lower inset of Fig. 12).

The distribution of the binding energy contribution coming from the other benzaldehyde molecules $\mathrm{P}\left(U_{\mathrm{b}}^{\mathrm{BA}}\right)$ has a peak at zero and another one around $-10 \mathrm{~kJ} / \mathrm{mol}$ in system $\mathrm{I}$. The zero energy peak is clearly coming from the isolated benzaldehyde molecules. The presence of the other, lower energy peak in the system of low surface coverage is somewhat surprising, as it indicates the tendency of the adsorbed benzaldehyde molecules for forming lateral selfaggregates rather than being always isolated from each other. At higher surface coverages, however, the $\mathrm{P}\left(U_{\mathrm{b}}^{\mathrm{BA}}\right)$ distribution becomes unimodal, having its peak around $-28 \mathrm{~kJ} / \mathrm{mol}$. This energy is given by the $\pi-\pi$ interaction of the neighboring benzene rings and by the dipole-dipole interaction of the neighboring aldehyde groups.

The distribution of the entire $U_{\mathrm{b}}$ binding energy exhibits a single peak around $-75 \mathrm{~kJ} / \mathrm{mol}$ both in system I and system II. The total energy accompanying the adsorption of a benzaldehyde molecule in these systems is rather low, certainly much lower than that of formaldehyde, ${ }^{16}$ being comparable with that of substrates forming multiple hydrogen bonds with the ice surface, such as methanol ${ }^{15}$ or formic acid. ${ }^{17}$ The lack of the possibility of multiple hydrogen bond formation is compensated here by the electron transfer-like interaction between the aromatic benzene ring of the benzaldehyde molecules in orientation $\alpha$ and the surface water $O$ atoms, and by the $\pi-\pi$ interaction of the benzene rings of neighboring benzaldehyde molecules in orientation $\beta$. Further 
increase of the surface coverage leads to somewhat weaker average attraction experienced by the individual molecules, as reflected in the fact that the peak of the $P\left(U_{\mathrm{b}}\right)$ distribution appears around $-50 \mathrm{~kJ} / \mathrm{mol}$ in system III. This weakening of the average binding energy is, however, overcompensated by the large increase of the number of adsorbed molecules, making the adsorption layer corresponding to the plateau of the adsorption isotherm particularly stable.

\section{Summary and Conclusions}

In this paper we presented a combined experimental and computer simulation investigation of the adsorption of benzaldehyde at the surface of ice at temperatures characteristic to the mid and upper troposphere. The power of using such a combined approach is clearly demonstrated. The simulated isotherm agrees almost perfectly with the experimental curve at $233 \mathrm{~K}$. Further, the experimental and simulated values of the heat of adsorption, i.e., $-61.4 \pm 9.7 \mathrm{~kJ} / \mathrm{mol}$ (experiment) and $-59.4 \mathrm{~kJ} / \mathrm{mol}$ (simulation) also agree with each other very well. The observed good reproduction of the experimental data by the simulation confirms the relevance of the computer model used, and validates the results of the detailed analyses of the simulated configurations.

It is found that benzaldehyde forms a rather stable saturated adsorption layer at the surface of ice in an about $1 \mathrm{~kJ} / \mathrm{mol}$ broad range of chemical potentials. This saturated adsorption layer is not monomolecular, but contains several molecules belonging to the second molecular layer, as well. At low surface coverages the adsorbed benzaldehyde molecules lie almost parallel with the ice surface, forming a hydrogen bond with a surface water molecule. This arrangement is further stabilized by the electron transfer interaction of a water $\mathrm{O}$ atom of high electronegativity and the delocalized $\pi$ electron system of the benzene ring. With increasing surface coverages the adsorbed benzaldehyde molecules increasingly compete for the surface area to be occupied, leading to the increasing preference of a nearly perpendicular alignment of the molecules to the surface. In this preferred alignment the aldehyde group is still turned toward the ice phase, and the adsorbed molecule forms a hydrogen bond with the surface waters. Finally, the first molecular layer is saturated by the adsorption of benzaldehyde molecules in a third orientation, i.e., being perpendicular to the ice surface and turning their aldehyde group to the vapor phase. However, simultaneously with the appearance of these latter molecules several 
adsorbed benzaldehyde molecules appears also in the second molecular layer, lying parallel with the ice surface. These molecules can stabilize each other via the electron transfer interaction between the perpendicular aligned molecules of the first molecular layer and the $\pi$ electron system of the benzene ring of the nearby lying molecules of the second layer. This interaction leads to the presence of traces of the second molecular layer in the stable saturated adsorption layer of benzaldehyde at the surface of ice.

Finally, this present work permits us to estimate the potential partitioning of benzaldehyde in tropospheric ice clouds. The fraction of benzaldehyde scavenged by ice surfaces contained in a cirrus cloud, $f_{\mathrm{BA} \text {, cirrus, }}$ can be estimated as follows:

$$
f_{\mathrm{BA}, \text { cirrus }}=\frac{[\mathrm{A}]_{\mathrm{Solid}}}{[\mathrm{A}]_{\mathrm{g}}+[\mathrm{A}]_{\mathrm{solid}}}=\frac{\mathrm{N}_{\mathrm{M}} \times \mathrm{K}_{\mathrm{ads}} \times \mathrm{D}_{\text {cirrus }}}{1+\mathrm{N}_{\mathrm{M}} \times \mathrm{K}_{\mathrm{ads}} \times \mathrm{D}_{\text {cirrus }}}
$$

where $D_{\text {cirrus }}$ is the surface area densities of ice ranging between $1 \times 10^{-4}$ and $1 \times 10^{-7} \mathrm{~cm}^{2} / \mathrm{cm}^{3}$ [57]. Even in the densest ice clouds and in the most favorable case experimentally studied here, i.e. $T=233 \mathrm{~K}$, only $0.05 \%$ of benzaldehyde could be adsorbed on pure ice surfaces at mid altitudes, which could be considered as negligible. Even if we assume that adsorption on ice surfaces may be more efficient at the lowest temperatures encountered in the upper troposphere, i.e. in the range of 213 - $193 \mathrm{~K}$, the atmospheric behavior of benzaldehyde can probably be only described by its gas phase chemistry, including both photolysis and $\mathrm{OH}$ reactions.

Acknowledgements. This project is supported by the Hungarian OTKA Foundation under project No. 75328, by the French Ministry of Research through the LEFE/CHAT program, by the region of Alsace and the REseau Alsace de Laboratoires en Ingénierie et Sciences pour l'Environnement (REALISE), by the MTA-CNRS bilateral collaboration program, and by the Hungarian-French Intergovernmental Science and Technology Program (BALATON). P. J. is a Bolyai János fellow of the Hungarian Academy of Sciences, which is gratefully acknowledged.

\section{References}

(1) Heymsfield, A. J.; Sabin, R. M. J. Atmos. Sci. 1989, 46, 2252.

(2) Seinfeld, J. H.; Pandis, S. N. Atmospheric Chemistry and Physics; Wiley: New York, 1998. 
(3) Hoyle, C. R.; Luo, B. P.; Peter, T. J. Atmos. Sci. 2005, 7, 2568.

(4) Arnold, F.; Bürger, V.; Droste-Fanke, B.; Grimm, F.; Krieger, A.; Schneider, J.; Stilp, T. Geophys. Res. Lett. 1997, 24, 3017.

(5) Mari, C.; Saüt, C.; Jacob, D.; Ravetta, F.; Anderson, B.; Avery, M. A.; Blake, D. R.; Brune, W. H.; Faloona, I.; Gregory, G. L.; Heikes, B. G.; Sachse, G. W.; Sandholm, S. T.; Singh, H. B.; Talbot, R. W.; Tan, D.; Vay, S. J. Geophys. Res. 2003, 108-D2, 8229.

(6) Singh, H.; Chen, Y.; Staudt, A.; Jacob, D.; Blake, D.; Heikes, B.; Snow, J. Nature 2001, 410, 1078.

(7) Singh, H.; Chen, Y.; Tabazadeh, A.; Fukui, Y.; Bey, I.; Yantosca, R.; Jacob, D.; Arnold, F.; Wohlfrom, K.; Atlas, E.; Flocke, F.; Blake, D.; Heikes, B.; Snow, J.; Talbot, R.; Gregory, G.; Sachse, G.; Vay, S.; Kondo, Y. J. Geophys. Res. 2000, 105, 3795.

(8) Laaksonen, A.; Hienola, J.; Kulmala, M.; Arnold, F. Geophys. Res. Lett. 1997, 24, 3009.

(9) Petitjean, M.; Mirabel, P.; Le Calvé, S. J. Phys. Chem. A 2009, 113, 5091.

(10) Peybernès, N.; Le Calvé, S.; Mirabel, P. J. Chem. Phys. B 2004, 108, 17425.

(11) Peybernès, N.; Marchand, C.; Le Calvé, S.; Mirabel, P. Phys. Chem. Chem. Phys. 2004, 6, 1277.

(12) Picaud, S.; Hoang, P. N. N.; Peybernès, N.; Le Calvé, S.; Mirabel, P. J. Chem. Phys. 2005, $122,194707$.

(13) Sokolov, O.; Abbatt, J. P. D. J. Phys. Chem. A 2002, 106, 775.

(14) Winkler, A. K.; Holmes, N. S.; Crowley, J. N. Phys. Chem. Chem. Phys. 2002, 4, 5270 .

(15) Jedlovszky, P.; Partay, L.; Hoang, P. N. M.; Picaud, S.; von Hessberg, P.; Crowley, J. N. J. Am. Chem. Soc. 2006, 128, 15300.

(16) Hantal, Gy.; Jedlovszky, P.; Hoang, P. N. M.; Picaud, S.; J. Phys. Chem. C 2007, 111, 14170.

(17) Jedlovszky, P.; Hantal, Gy.; Neuróhr, K.; Picaud, S.; Hoang, P. N. M.; von Hessberg, P.; Crowley, J. N. J. Phys. Chem. C 2008, 112, 8976.

(18) Hantal, Gy.; Jedlovszky, P.; Hoang, P. N. M.; Picaud, S. Phys. Chem. Chem. Phys. 2008, $10,6369$.

(19) Dominé, F.; Rey-Hanot, L. Geophys. Res. Lett. 2002, 29, 1873. 
(20) Adams, D. J. Mol. Phys. 1975, 29, 307.

(21) M. P. Allen, D. J. Tildesley Computer Simulation of Liquids; Clarendon: Oxford, 1987.

(22) Muller, E. A.; Rull, L. F.; Vega, L. F.; Gubbins, K. E. J. Phys. Chem. 1996, 100, 1189.

(23) Muller, E. A.; Hung, F. R.; Gubbins, K. E. Langmuir 2000, 16, 5418.

(24) Stirolo, A.; Chialvo, A. A.; Gubbins, K. E.; Cummings, P. T. J. Chem. Phys. 2005, $122,234712$.

(25) Moulin, F.; Picaud, S.; Hoang, P. N. M.; Pártay, L. B.; Jedlovszky, P. Mol. Simul. 2006, 32, 487.

(26) Moulin, F.; Picaud, S.; Hoang, P. N. M.; Jedlovszky, P. J. Chem. Phys. 2007, 127, 164719.

(27) Moulin, F.; Hoang, P. N. M.; Picaud, S.; Pártay, L. B.; Jedlovszky, P. Comp. Lett. 2008, 4, 105.

(28) Garberoglio, G. Langmuir 2007, 23, 12154.

(29) Puibasset, J.; Pellenq, R. J. M. J. Chem. Phys. 2003, 118, 5613.

(30) Puibasset, J.; Pellenq, R. J. M. J. Chem. Phys. 2005, 122, 094704.

(31) Szőri, M.; Jedlovszky, P.; Roeselová, M. Phys. Chem. Chem. Phys., submitted.

(32) Daub, C. D.; Patey G. N.; Jack, D. B.; Sallabi A. K. J. Chem. Phys. 2006, 124, 114706.

(33) Croteau, T.; Bertram, A. K.; Patey, G. N. J. Phys. Chem. A 2008, 112, 10708.

(34) Croteau, T.; Bertram, A. K.; Patey, G. N. J. Phys. Chem. A 2009, 113, 7826.

(35) Tombácz, E.; Hajdú, A.; Illés, E.; László, K.; Garberoglio, G.; Jedlovszky, P. Langmuir 2009, 25, 13007.

(36) Atkinson, R. Gas-phase tropospheric chemistry of organic compounds; American Chemical Society; American Institute of Physics for the National Institute of Standards and Technology: Washington; Woodbury, 1994.

(37) Journet, E.; Le Calvé, S.; Mirabel, P. J. Phys. Chem. B 2005, 109, 14112.

(38) Kerbrat, M.; Le Calvé, S.; Mirabel, P. J. Phys. Chem. A 2007, 111, 925.

(39) Taylor, G. Proc.Roy.Soc.London 1953, 219, 186.

(40) Mahoney, M.; Jorgensen, W. L. J. Chem. Phys. 2000, 112, 8910. 
(41) Vega, C.; Sanz, E.; Abascal, J. L. F. J. Chem. Phys. 2005, 122, 114507.

(42) Jorgensen, W. L.; Maxwell, D. S.; Tirado-Rives, J. J. Am. Chem. Soc. 1996, 118, 11225.

(43) Canneaux, S.; Soetens, J. C.; Henon, E.; Bohr, F. Chem. Phys. 2006, 327, 212.

(44) Mezei, M. MMC: Monte Carlo program for simulation of molecular assemblies. URL: http://inka.mssm.edu/ mezei/mmc.

(45) Mezei, M. Mol. Phys. 1980, 40, 901.

(46) Mezei, M. Mol. Phys. 1987, 61, 565. Erratum: 1989, 67, 1207.

(47) Kemball, C. Proceedings of the Royal Society of London Series a-Mathematical and Physical Sciences 1946, 187, 73.

(48) Kemball, C.; Rideal, E. K. Proceedings of the Royal Society of London Series aMathematical and Physical Sciences 1946, 187, 53.

(49) Carmichael, H. J. Chem. Edu. 1976, 53, 695.

(50) Bartels, T.; Eichler, B.; Zimmermann, P.; Gäggeler, H. W.; Ammann, M. Atmos. Chem. Phys. 2002, 2, 235.

(51) Ambrose, D.; Connett, J. E.; Green, J. H. S.; Hales, J. L.; Head, A. J.; Martin, J. F. J. Chem. Thermodyn. 1975, 7, 1143.

(52) Atkins, P. W. Physical chemistry, $5^{\text {th }}$ ed.; Oxford University Press: Oxford, 1994.

(53) Sinnot, R. K. Chemical Engineering Design, Coulson and Richardson's Chemical Engineering Series, Vol. 6, $4^{\text {th }}$ ed.; Elsevier Butterworth-Heinemann: Oxford, 2005.

(54) Jedlovszky, P.; Vincze, Á.; Horvai, G. J. Chem. Phys. 2002, 117, 2271.

(55) Jedlovszky, P.; Vincze, Á.; Horvai, G. Phys. Chem. Chem. Phys. 2004, 6, 1874.

(56) Bahr, S.; Kempter, V.; J. Chem. Phys. 2007, 127, 074707.

(57) Solomon, S.; Borrmann, S.; Garcia, R. R.; Portmann, R.; Thomason, L.; Poole, L. R.; Winker, D.; McCormick, M. P. J. Geophys. Res. 1997, 102, 21411. 


\section{Tables}

Table 1. Data of the Adsorption Isotherm of Benzaldehyde on Ice, as Obtained from the Simulations

\begin{tabular}{|c|c|c|c|}
\hline$\mu / \mathrm{kJ} \mathrm{mol}^{-1}$ & $\langle N\rangle$ & $\Pi / \mu \mathrm{mol} \mathrm{m}{ }^{-2}$ & $p / p_{0}$ \\
\hline-60.66 & 280.0 & & \\
\hline-61.05 & 280.0 & & \\
\hline-61.10 & 114.7 & 6.84 & 0.988 \\
\hline-61.15 & 114.3 & 6.82 & 0.963 \\
\hline-61.24 & 113.0 & 6.74 & 0.916 \\
\hline-61.34 & 112.4 & 6.71 & 0.872 \\
\hline$-61.44^{a}$ & 111.7 & 6.66 & 0.829 \\
\hline-61.53 & 112.4 & 6.70 & 0.789 \\
\hline-61.63 & 112.9 & 6.73 & 0.750 \\
\hline-61.73 & 113.7 & 6.78 & 0.714 \\
\hline-61.82 & 112.1 & 6.68 & 0.679 \\
\hline-61.92 & 110.1 & 6.57 & 0.646 \\
\hline-62.01 & 111.2 & 6.63 & 0.614 \\
\hline$-62.21^{b}$ & 59.67 & 3.56 & 0.556 \\
\hline-62.59 & 45.13 & 2.69 & 0.455 \\
\hline-62.98 & 32.63 & 1.95 & 0.373 \\
\hline-63.36 & 29.31 & 1.75 & 0.305 \\
\hline$-63.75^{c}$ & 21.86 & 1.30 & 0.250 \\
\hline-64.14 & 18.77 & 1.12 & 0.204 \\
\hline-64.52 & 13.09 & 0.781 & 0.167 \\
\hline-64.91 & 12.15 & 0.725 & 0.137 \\
\hline-65.29 & 7.61 & 0.454 & 0.112 \\
\hline-65.68 & 7.35 & 0.438 & $9.19 \times 10^{-2}$ \\
\hline-66.07 & 7.47 & 0.446 & $7.52 \times 10^{-2}$ \\
\hline-66.45 & 5.18 & 0.309 & $6.16 \times 10^{-2}$ \\
\hline-67.42 & 3.66 & 0.218 & $9.19 \times 10^{-2}$ \\
\hline-68.38 & 2.66 & 0.099 & $3.73 \times 10^{-2}$ \\
\hline-69.35 & 1.98 & 0.118 & $2.27 \times 10^{-2}$ \\
\hline-70.31 & 0.99 & 0.059 & $8.33 \times 10^{-3}$ \\
\hline
\end{tabular}

${ }^{\mathrm{a}}$ system I ${ }^{\mathrm{b}}$ system II ${ }^{\mathrm{c}}$ systemIII 
Table 2: Values of $N_{\mathrm{M}} \times K_{\text {ads }}(T), K(T), \Delta G_{\text {ads }}$ and $\Delta H_{\text {ads }}$ for Benzaldehyde Adsorption on Pure Ice at 233, 243 and 253 K. The Quoted Errors Correspond to $2 \sigma$ Level + 5\% (See the Text).

\begin{tabular}{cccccc}
\hline \hline$T / \mathrm{K}$ & $N_{\mathrm{M}} \times K_{\mathrm{ads}} / \mathrm{cm}^{\mathrm{a}}$ & $R^{2}$ & $K \times 10^{-7 \mathrm{a}}$ & $-\Delta G_{\mathrm{ads}} / \mathrm{kJ} \mathrm{mol}^{-1 \mathrm{~b}}$ & $-\Delta H_{\mathrm{ads}} / \mathrm{kJ} \mathrm{mol}^{-1 \mathrm{~b}}$ \\
\hline 233 & $5.26( \pm 0.52)$ & 0.93 & $8.94( \pm 0.88)$ & $35.5( \pm 2)$ & $61.4( \pm 9.7)$ \\
243 & $1.79( \pm 0.24)$ & 0.88 & $3.04( \pm 0.41)$ & $34.8( \pm 2)$ & $61.8( \pm 9.9)$ \\
253 & $0.80( \pm 0.11)$ & 0.86 & $1.36( \pm 0.19)$ & $34.5( \pm 2)$ & $62.7( \pm 10.0)$ \\
\hline \hline
\end{tabular}

${ }^{\mathrm{a} D}$ Determined from the slopes of the plots of $N$ versus benzaldehyde concentration (see eq. 5) ${ }^{\mathrm{b}} \Delta G_{\text {ads }}$ is obtained from eq. 3. $\Delta H_{\text {ads }}$ is derived from eq. 3, where $\Delta S_{\text {ads }}$ was set to be $-111.3 \mathrm{~J} / \mathrm{K} \mathrm{mol}$. 


\section{Figure legend}

Figure 1. Gas phase concentration of benzaldehyde as a function of time during its adsorption on ice surfaces at $233 \mathrm{~K}$ (with [benzaldehyde] gas phase $=5.3 \times 10^{12}$ molecules $/ \mathrm{cm}^{3}$ ).

Figure 2. Adsorption isotherms of benzaldehyde on pure ice at $233 \mathrm{~K}$ (full circles), $243 \mathrm{~K}$ (open circles), and $253 \mathrm{~K}$ (full triangles). The solid lines correspond to the linear fits according to eq. 5 .

Figure 3. Plot of $K$ as a function of $1 / T$ corresponding to benzaldehyde adsorption on pure ice. The adsorption enthalpy is derived from the slope according to eq. 3 .

Figure 4. Comparison of adsorption isotherms of benzaldehyde (full circles) and acetaldehyde $^{9}$ (open circles) on pure ice at $233 \mathrm{~K}$. Plot of the number of molecules adsorbed per surface unit versus the absolute gas phase concentration of aldehyde.

Figure 5. Average number of benzaldehyde molecules in the basic simulation box as a function of the benzaldehyde chemical potential. The arrows indicate the three systems considered for detailed analysis.

Figure 6. Instantaneous equilibrium snapshot of the benzaldehyde layer adsorbed at the ice surface as taken out from the simulations of system I (top row), system II (middle row) and system III (bottom row). The snapshots are shown both in side view (first column) and in top view (second column).

Figure 7. Comparison of the experimental (full circles) and simulated (open circles) adsorption isotherms of benzaldehyde on ice at $233 \mathrm{~K}$. The error bars of the simulated data points are always smaller than the symbols. The inset shows the same comparison in the entire $0 \leq p_{\text {rel }} \leq 1$ pressure range. The arrows indicate the three systems considered for detailed analysis. 
Figure 8. Number density profile of the adsorbed benzaldehyde molecules in system I (dashdotted line), system II (dashed line) and system III (solid line). The number density profile of the surface waters is also indicated (dotted line). The insets show the contribution of the $\alpha$ (full circles), $\beta$ (open circles) and $\gamma$ (asterisks) oriented benzaldehyde molecules to the total density profile in systems II (upper inset) and III (lower inset).

Figure 9. Definition of the local Cartesian frame fixed to the individual benzaldehyde molecules, and of the polar angles $\vartheta$ and $\phi$ of the surface normal vector, pointing, by our convention, away from the ice phase, $\underline{X}$, in this frame.

Figure 10. Orientational map of the adsorbed benzaldehyde molecules in systems I (first map), II (second map), and III (third map). Darker colors indicate higher probabilities. The peaks corresponding to the preferred benzaldehyde orientations are marked by $\alpha, \beta$ and $\gamma$ on the maps. The three preferred benzaldehyde orientations are also illustrated. $\underline{X}$ is the surface normal vector pointing away from the ice phase.

Figure 11. Illustration of the strong attractive interactions stabilizing the adsorbed benzaldehyde molecules in different orientations. (a) Hydrogen bonding between a surface water and an adsorbed benzaldehyde molecule of orientation $\alpha$. (b) Hydrogen bonding between a surface water and an adsorbed benzaldehyde molecule of orientation $\beta$. (c) Electron transfer-like interaction between a benzaldehyde molecule of orientation $\gamma$ in the first molecular layer and another benzaldehyde molecule of orientation $\alpha$ in the second molecular layer. $\underline{X}$ is the surface normal vector pointing away from the ice phase.

Figure 12. Distribution of the total binding energy of an adsorbed benzaldehyde molecule (i.e., the energy of its interaction with the rest of the system, bottom panel), and its contributions coming from the interaction with the other adsorbed benzaldehyde molecules (middle panel) and with the ice phase (top panel) in systems I (dash-dotted line), II (dashed line), and III (solid line). The insets show the contribution of the $\alpha$ (full circles), $\beta$ (open circles) and $\gamma$ (asterisks) oriented benzaldehyde molecules to the ice contribution of the binding energy in systems II (upper inset) and III (lower inset). 
Figure 1.

Petitjean et $a l$.

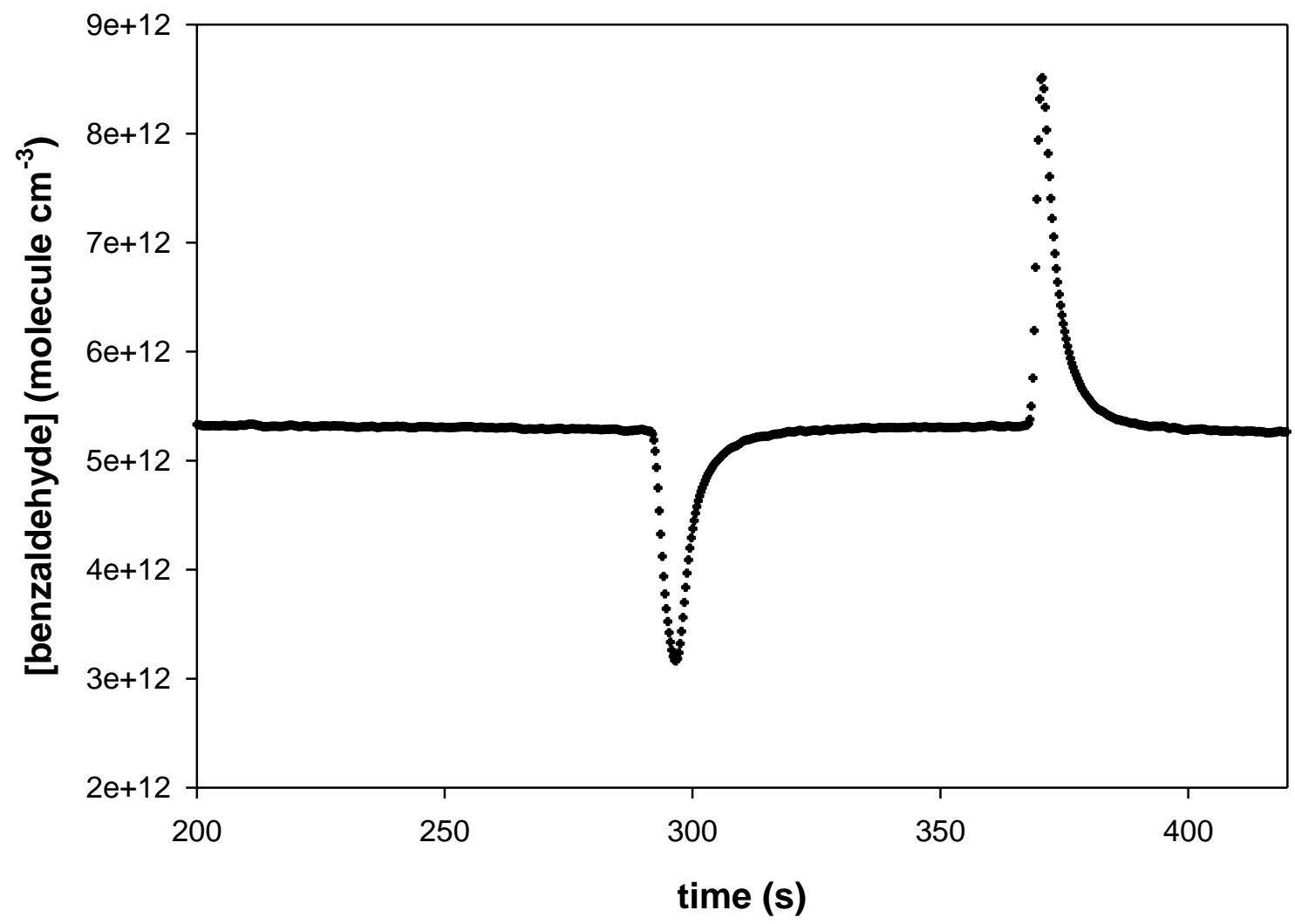


Figure 2.

Petitjean et $a l$.

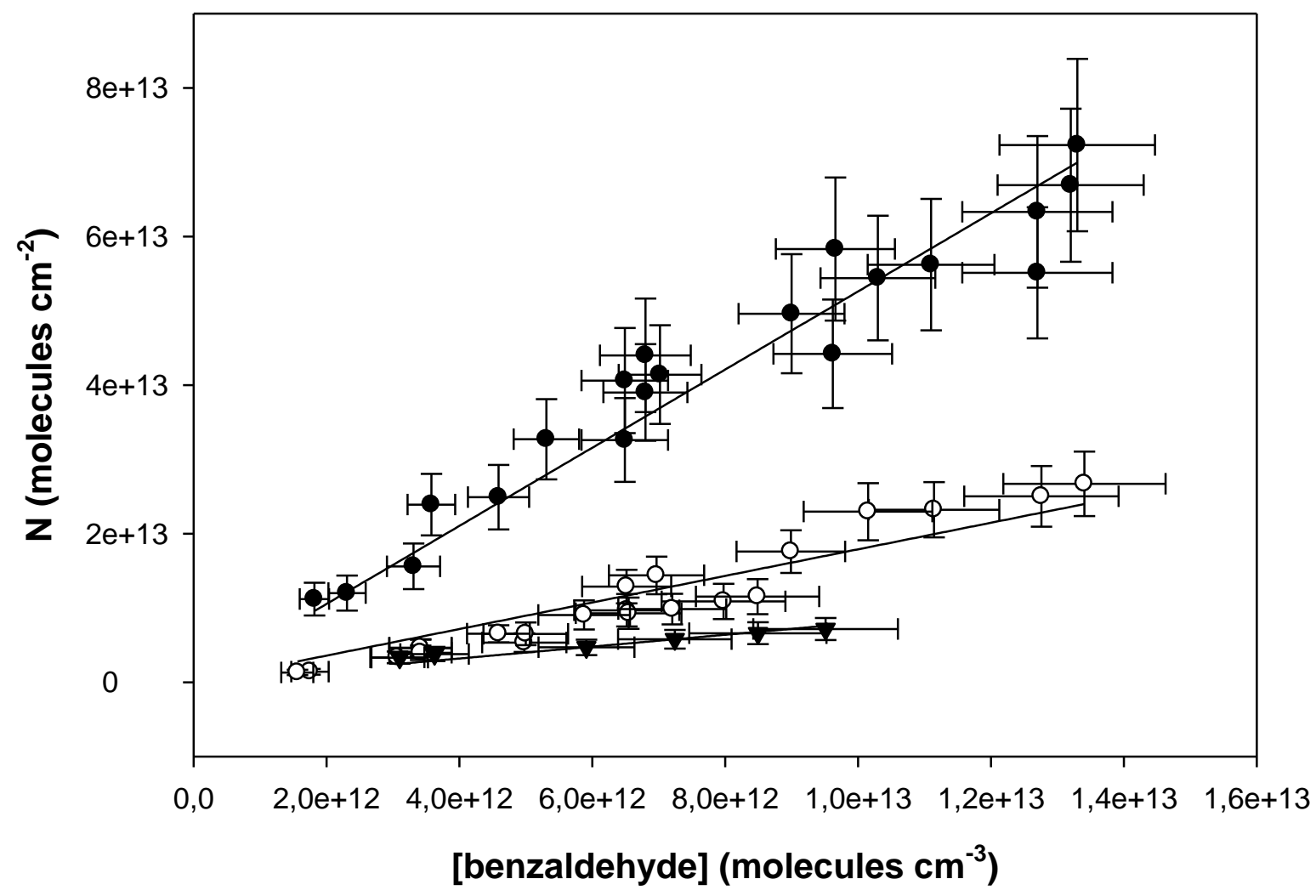


Figure 3.

Petitjean et $a l$.

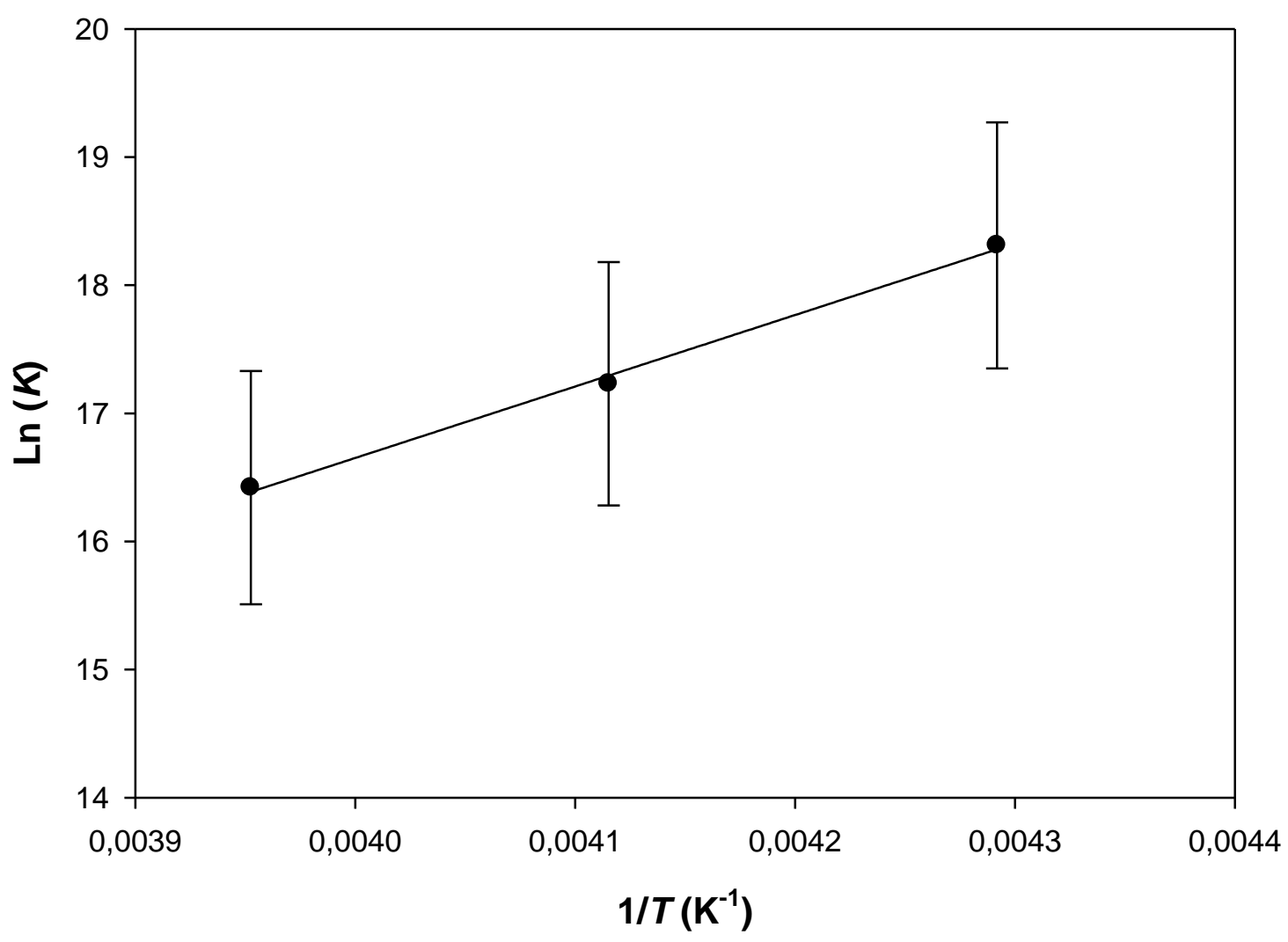


Figure 4.

Petitjean et $a l$.

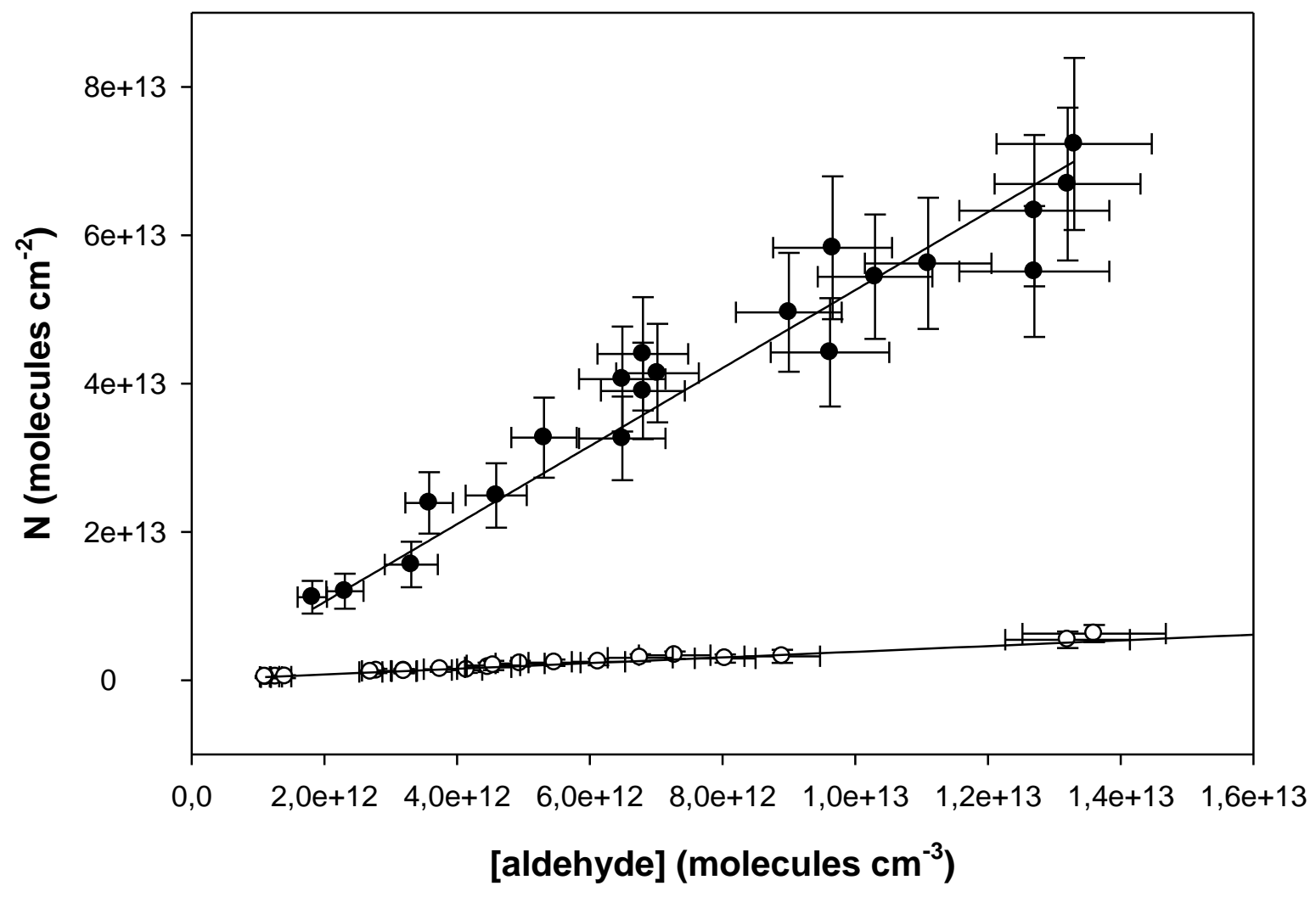


Figure 5.

Petitjean et $a l$.

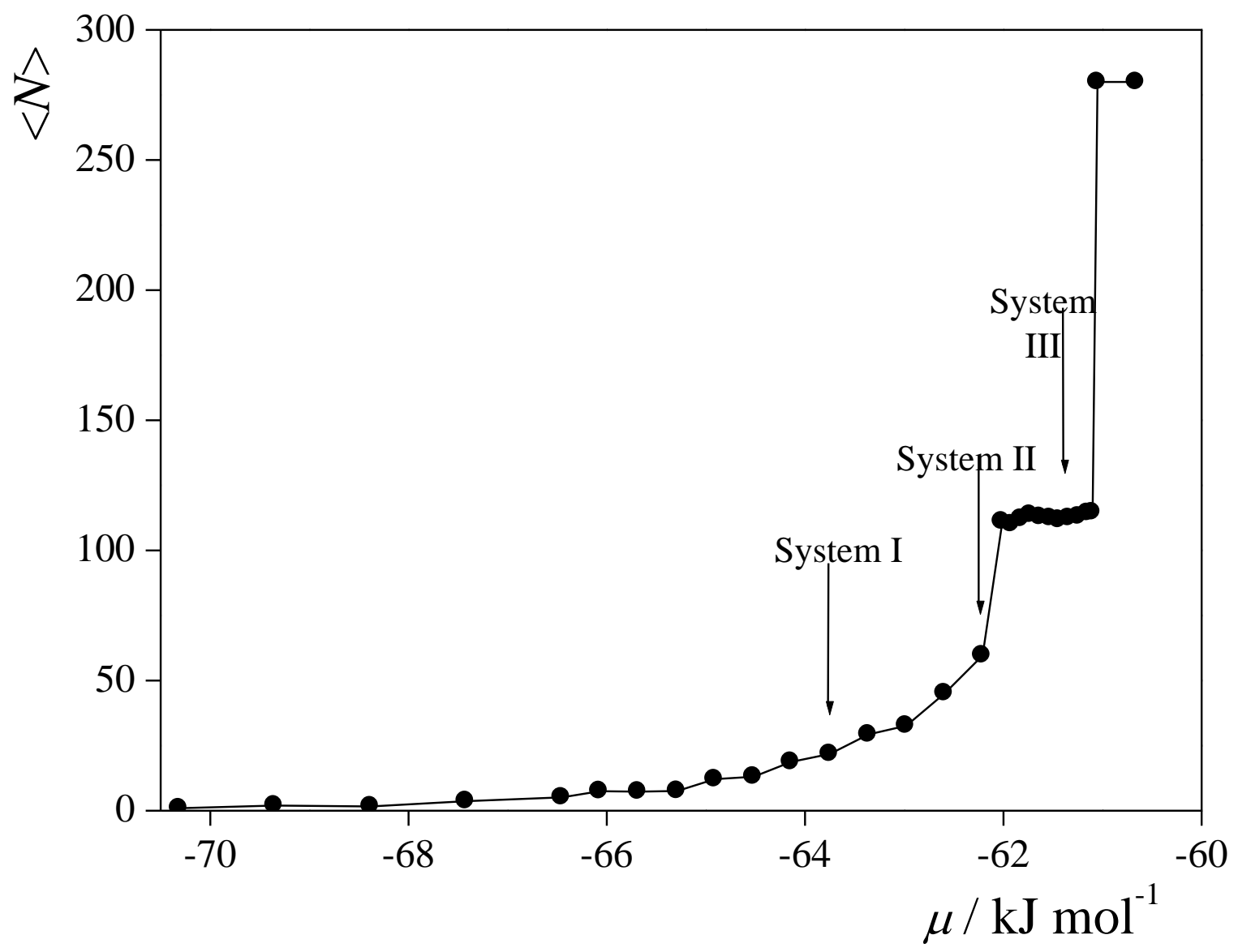



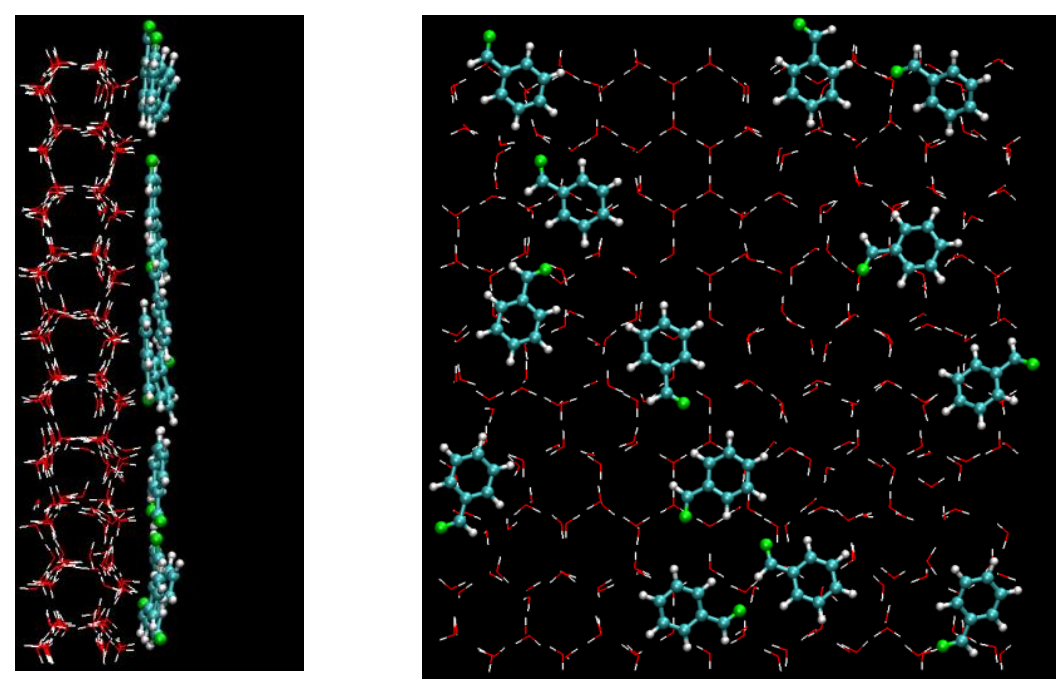

Figure 6.

Petitjean et $a l$.
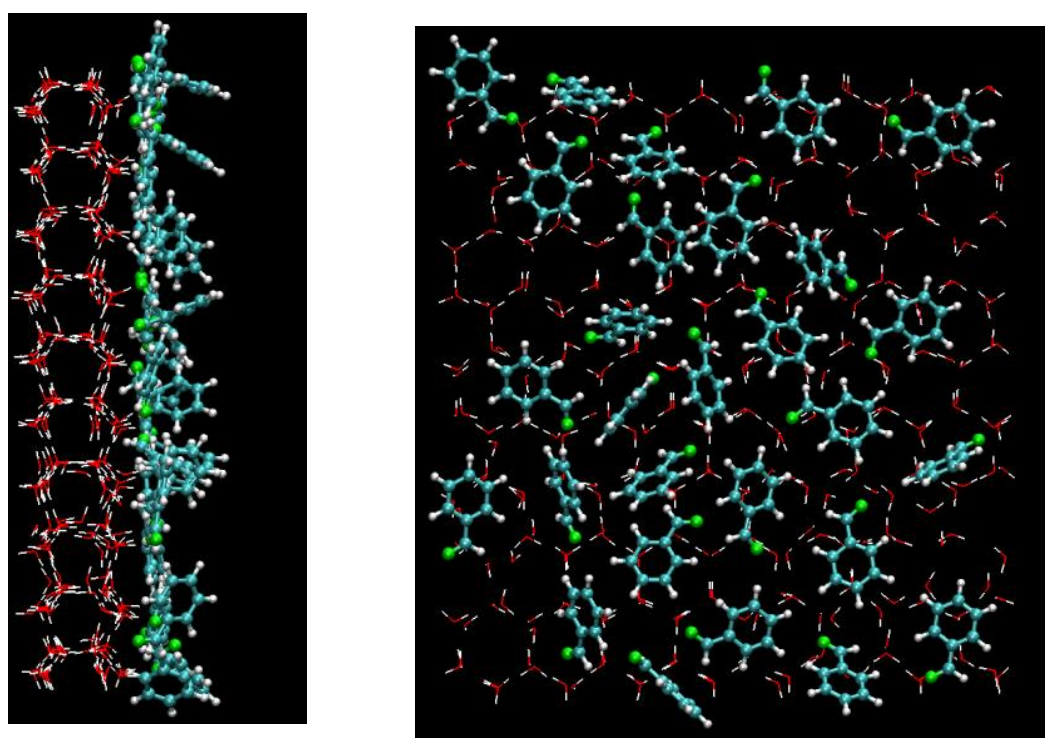

System I

System II
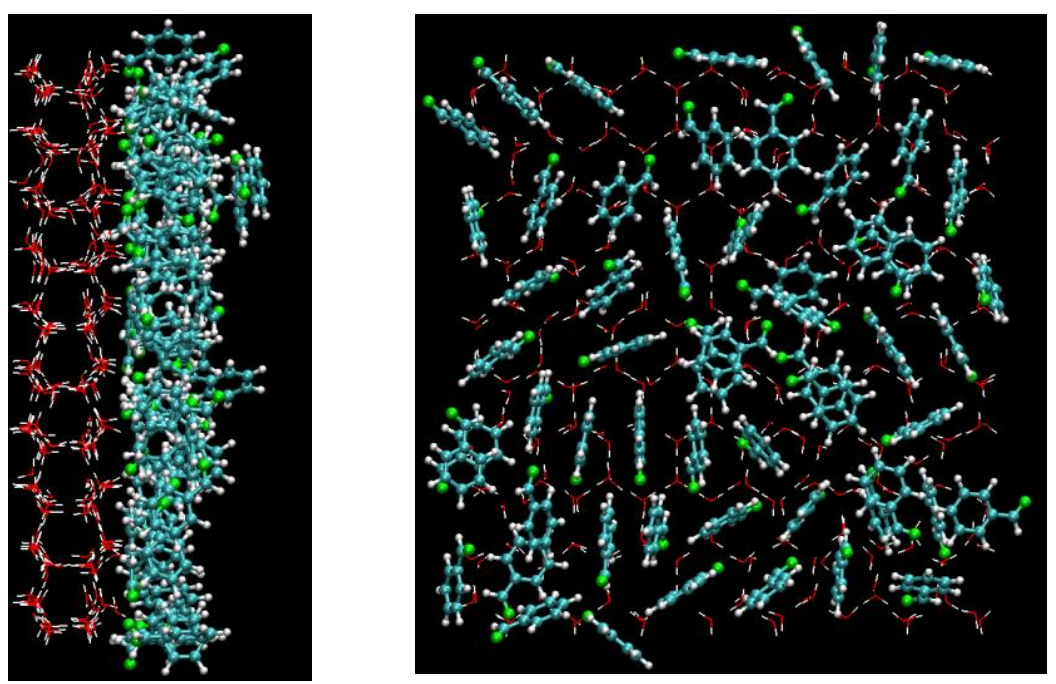

System III 
Figure 7.

Petitjean et $a l$.

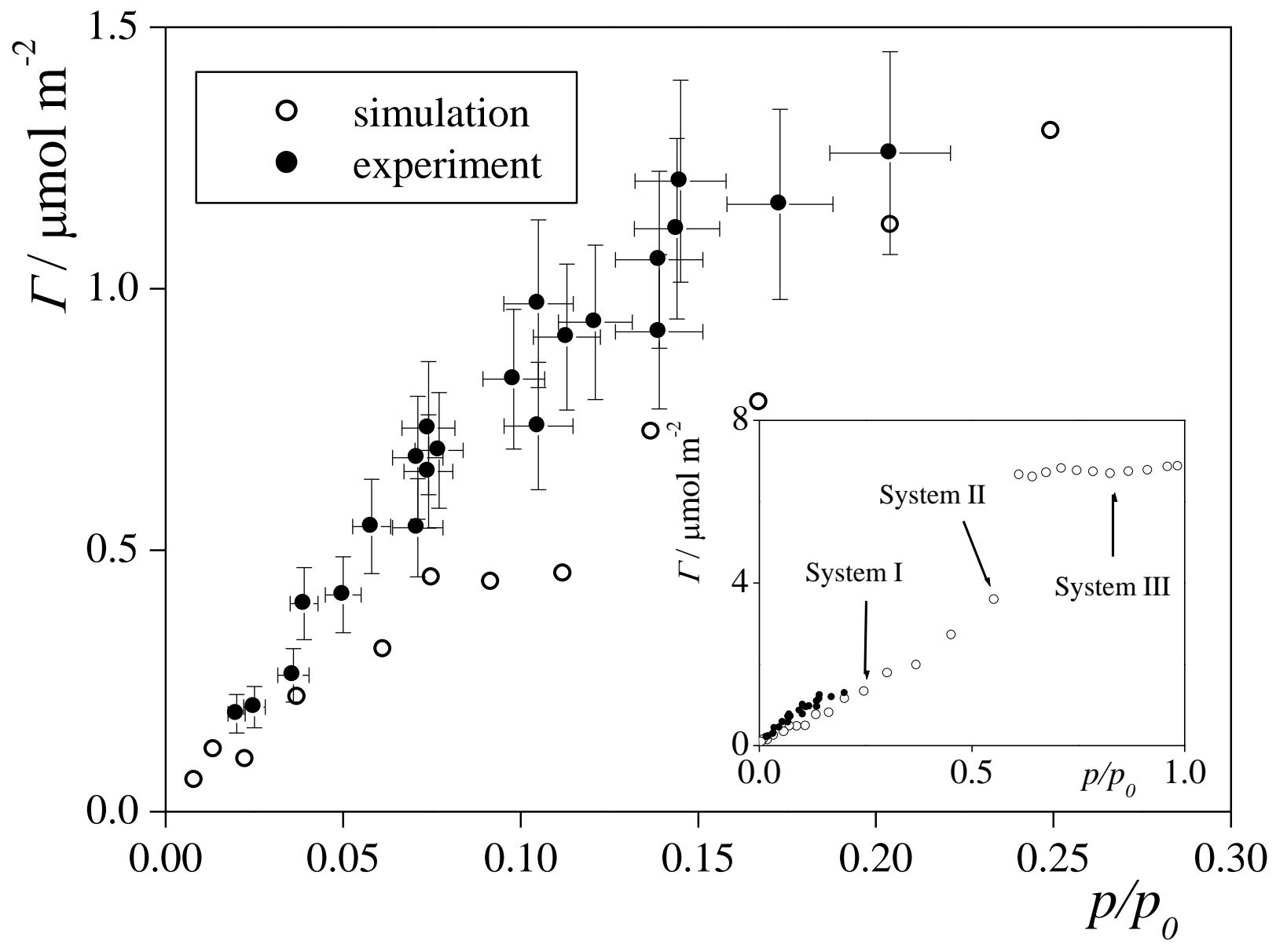


Figure 8.

Petitjean et $a l$.

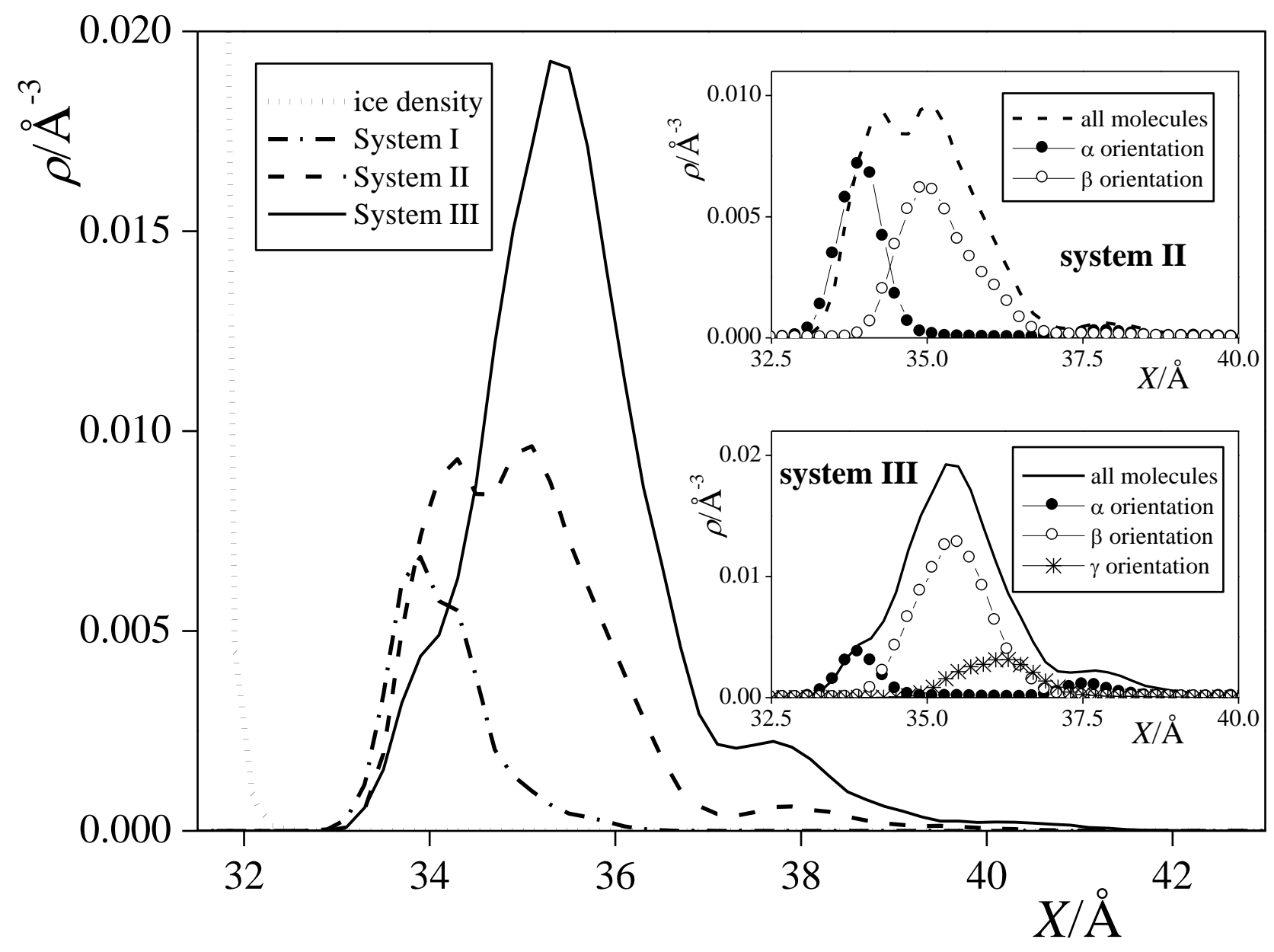


Figure 9.

Petitjean et $a l$.

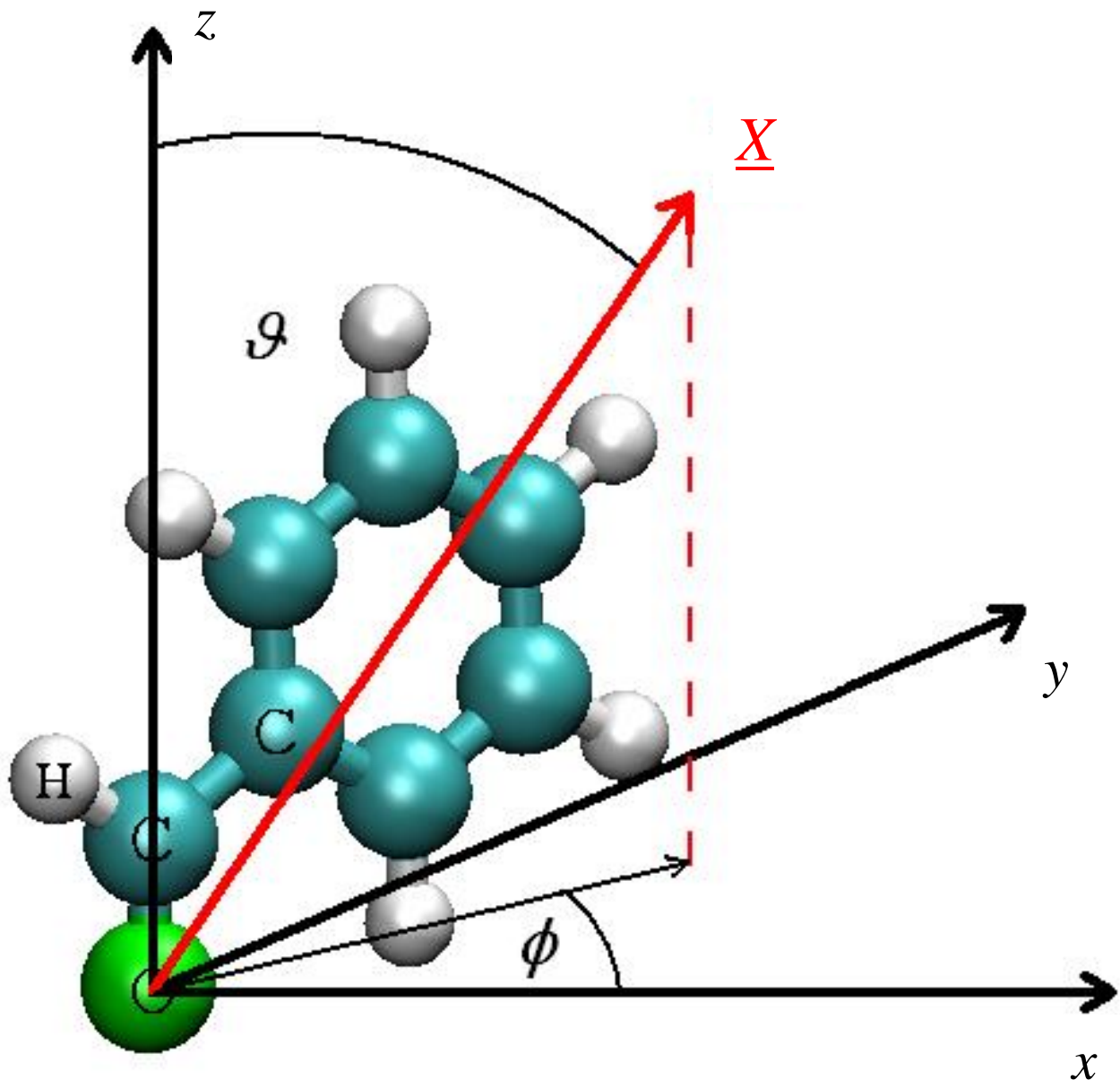


Figure 10.

Petitjean et $a l$.

system I

system II

system III
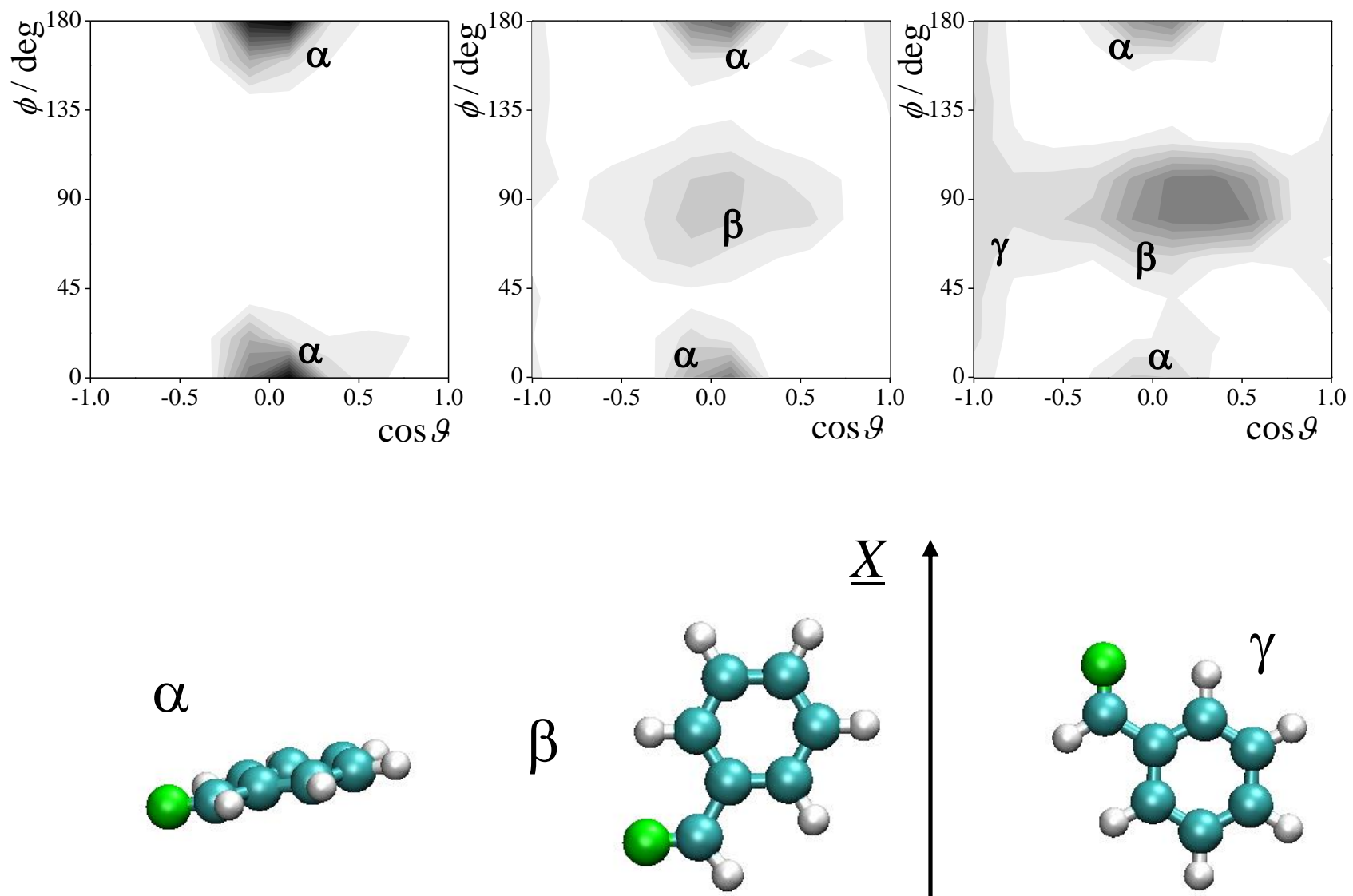
Figure 11.

Petitjean et al.

(a)

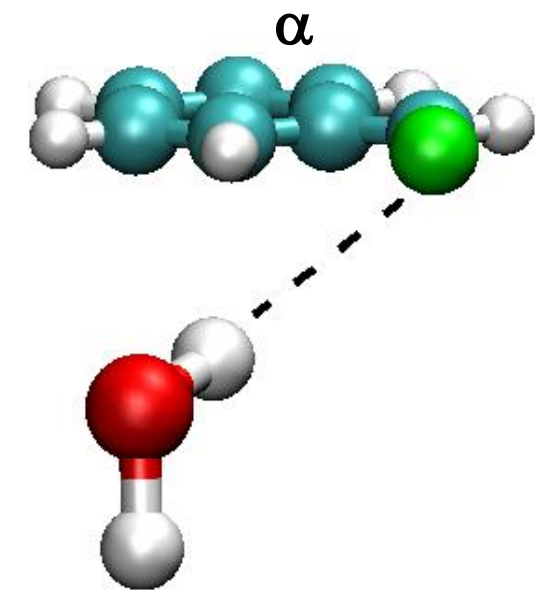

^ $\underline{X}$

(c)

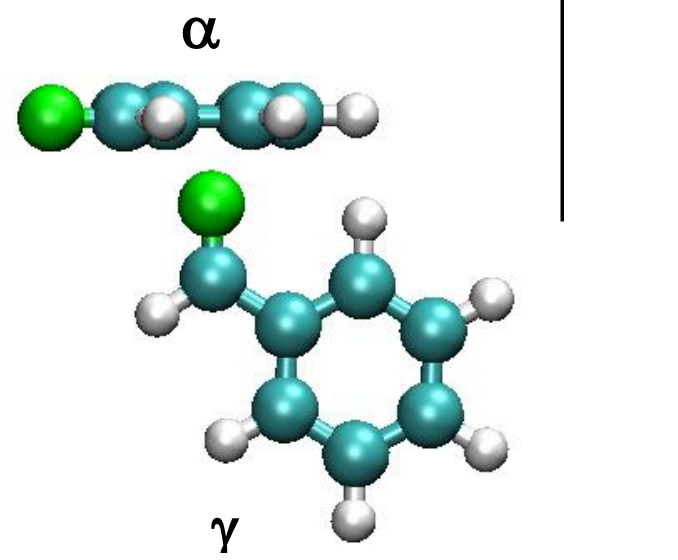

(b)

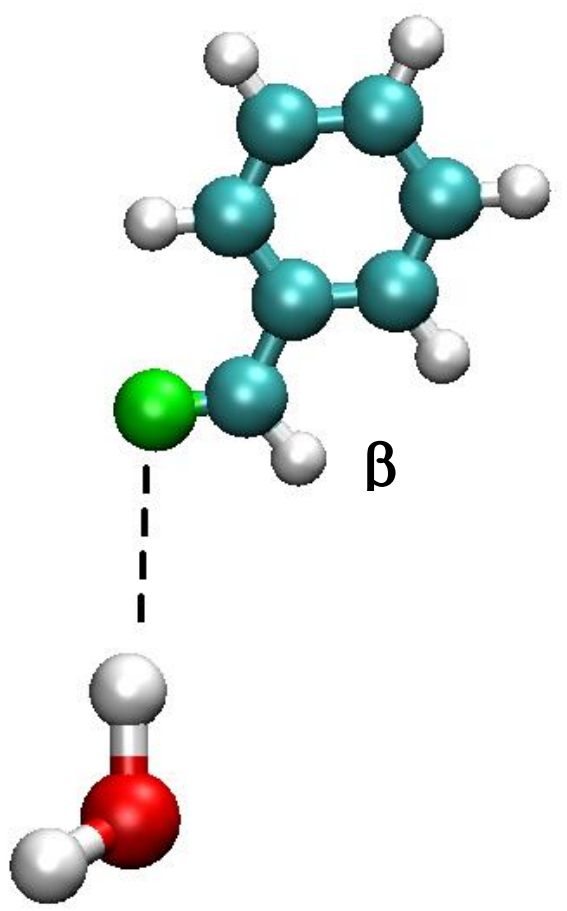


Figure 12.

Petitjean et $a l$.

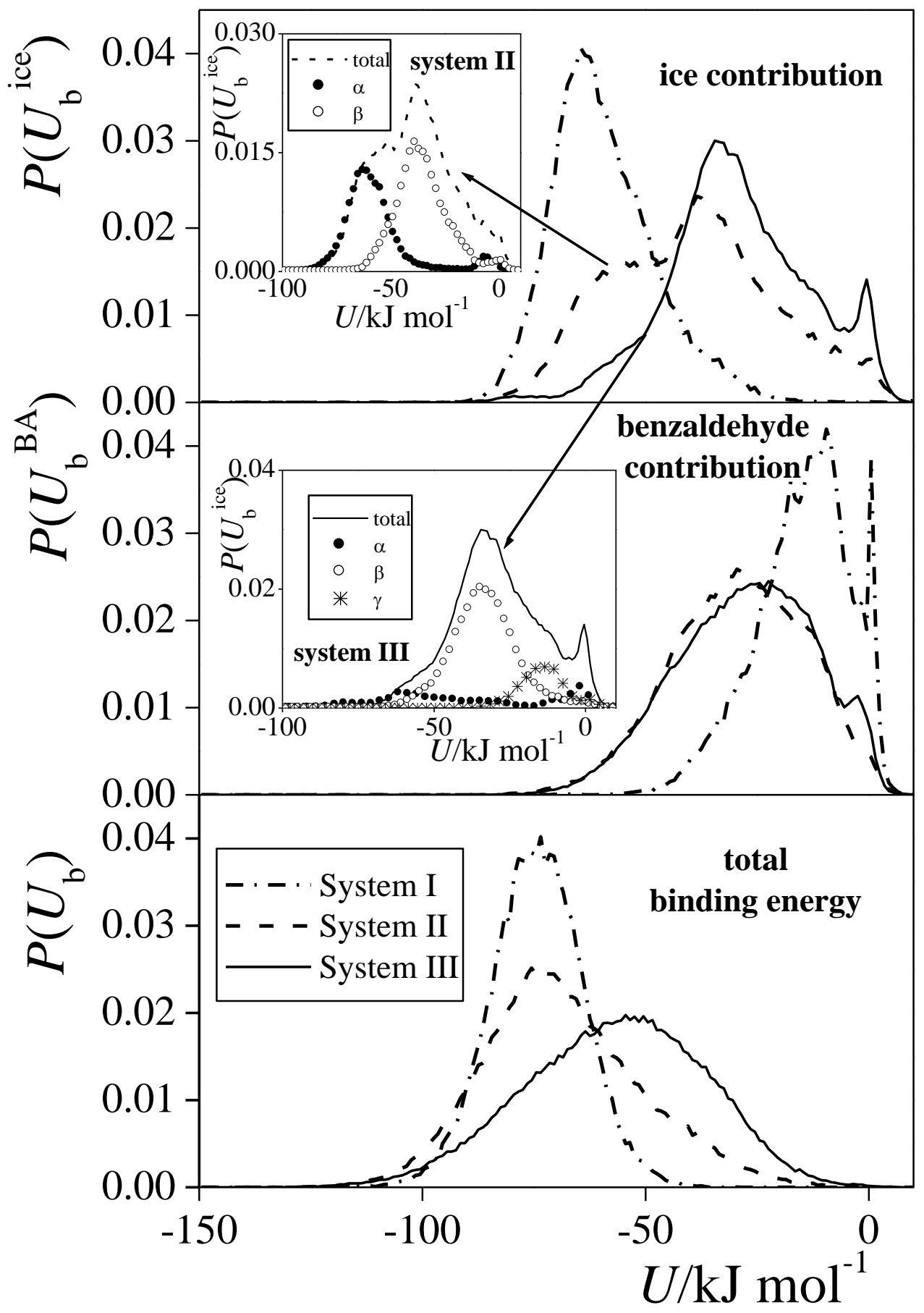


Table of Contents Graphics:

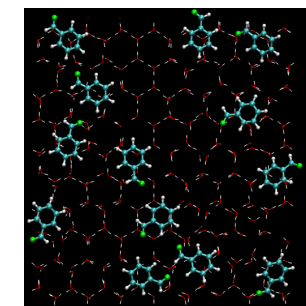

low surface coverage

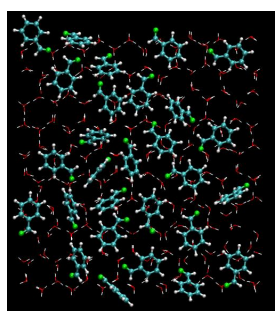

intermediate surface coverage adsorption layer

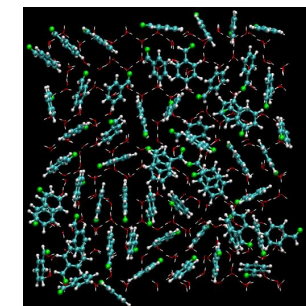

saturated 